\title{
Peer Effects in the WorkPlace ${ }^{*}$
}

\author{
Thomas Cornelissen \\ Christian Dustmann \\ Uta Schönberg
}

\section{This Version: July 2016}

\begin{abstract}
Existing evidence on peer effects in the productivity of coworkers stems from either laboratory experiments or real-word studies referring to a specific firm or occupation. In this paper we aim at providing more generalizable results by investigating a large local labor market, with a focus on peer effects in wages rather than productivity. Our estimation strategy — which links the average permanent productivity of workers' peers to their wages-circumvents the reflection problem and accounts for endogenous sorting of workers into peer groups and firms. On average over all occupations, and in the type of high skilled occupations investigated in studies on knowledge spillover, we find only small peer effects in wages. In the type of low skilled occupations analyzed in extant studies on social pressure, in contrast, we find larger peer effects, about half the size of those identified in similar studies on productivity. (JEL J24, J31)
\end{abstract}

Keywords: Peer effects, productivity, wage determination

\footnotetext{
* Correspondence: Thomas Cornelissen, Department of Economics, University of York, Heslington, York YO10 5DD, United Kingdom (email: thomas.cornelissen@york.ac.uk]; Christian Dustmann, Department of Economics, University College London and CReAM, 30 Gordon Street, London WC1H 0AX, United Kingdom (email: c.dustmann@ucl.ac.uk); Uta Schönberg, Department of Economics, University College London, CReAM and IAB, 30 Gordon Street, London WC1H 0AX, United Kingdom (email: u.schoenberg@ucl.ac.uk.

We are grateful to Josh Kinsler for comments and for sharing program code.

Uta Schönberg acknowledges funding by the European Research Council (ERC) Starter grant SPILL. Christian Dustmann acknowledges funding by an ERC Advanced Grant.
} 
The communication and social interaction between coworkers that necessarily occur in the workplace facilitate comparison of individual versus coworker productivity. In this context, workers whose productivity falls behind that of coworkers, or falls short of a social norm, may experience personal feelings of guilt or shame. They may then act on these feelings by increasing their own efforts, a mechanism referred to in the economic literature as "peer pressure." Social interaction in the workplace may also lead to "knowledge spillover" in which coworkers learn from each other and build up skills that they otherwise would not have. Such productivity enhancing peer effects may exacerbate initial productivity differences between workers and increase long-term inequality when high quality workers cluster together in the same peer groups. Moreover, while knowledge spillover is an important source of agglomeration economies (e.g., Lucas, 1988; Marshall, 1890), social pressure further implies that workers respond not only to monetary but also to social incentives, which may alleviate the potential freerider problem inherent whenever workers work together in a team (Kandel and Lazear, 1992).

Despite the economic importance of peer effects, empirical evidence on such effects in the workplace is as yet restricted to a handful of studies referring to very specific settings, based on either laboratory experiments or on real-world data from a single firm or occupation. For instance, Mas and Moretti's (2009) study of one large supermarket chain provides persuasive evidence that workers' productivity increases when they work alongside more productive coworkers, a finding that they attribute to increased social pressure. Likewise, a controlled laboratory experiment by Falk and Ichino (2006) reveals that students recruited to stuff letters into envelopes work faster when they share a room than when they sit alone. ${ }^{1}$ For peer effects in

\footnotetext{
1 Other papers focusing on social pressure include Kaur, Kremer, and Mullainathan (2010), who report productivity spillovers among data-entry workers seated next to each other in an Indian company. Similarly, Bandiera, Barankay, and Rasul (2010) find that soft-fruit pickers in one large U.K. farm are more productive if at least one of their more able friends is present on the same field but less productive if they are the most able among their friends. Peer pressure is also a likely channel in Chan et al.'s (2014) finding of peer effects in productivity among salespersons of a department store, and in the general pattern of network effects in the productivity of call-
} 
the workplace induced by knowledge spillover, however, the evidence is mixed. Whereas Waldinger (2012) finds little evidence for knowledge spillover among scientists in the same department in a university, Azoulay, Graff Zivin, and Wang (2010) and Jackson and Bruegemann (2009) find support for learning from coworkers among medical science researchers and teachers, respectively. ${ }^{2}$ In a comprehensive meta-analysis of peer effects in coworker productivity covering both high and low-skilled tasks, Herbst and Mas (2015) report a remarkable similarity between the cross-study average peer effect from laboratory experiments and field studies. Nonetheless, although existing studies provide compelling and clean evidence for the existence (or absence) of peer effects in specific settings, it is unclear to what extent their findings, which are all based on laboratory experiments or real-word studies referring to a specific firm or occupation, apply to the labor market in general.

In this paper, therefore, we go beyond the existing literature to investigate peer effects in the workplace for a representative set of workers, firms, and sectors. Our unique data set, which encompasses all workers and firms in one large local labor market over nearly two decades, allows us to compare the magnitude of peer effects across detailed sectors. It thus provides a rare opportunity to investigate whether the peer effects uncovered in the literature are confined to the specific firms or sectors studied or whether they carry over to the general labor market, thus shedding light on the external validity of the existing studies. At the same time, our comparison

center workers found by Lindquist et al. (2015). In work that analyzes regional shirking differentials in a large Italian bank, Ichino and Maggi (2000) find that average peer absenteeism has an effect on individual absenteeism. A controlled field experiment by Babcock et al. (2011) suggests that agent awareness of their own efforts' effect on known peer payoffs creates incentives possibly mediated by a form of social pressure.

${ }^{2}$ In related work, Waldinger (2010) shows that faculty quality positively affects doctoral student outcomes, while Serafinelli (2013) provides evidence that worker mobility from high- to low-wage firms increases the productivity of low-wage firms, which is consistent with knowledge spillover. The findings by Lindquist et al. (2015) and De Grip and Sauermann (2012) suggest knowledge transfer to be a relevant source of productivity spillover when trained and untrained workers interact. Other studies (e.g., Guryan, Kroft, and Notowidigdo, 2009; Gould and Winter, 2009) analyze such knowledge spillover between team mates in sports. For a non-technical discussion of evidence and implications of peer effects in coworker productivity see also Cornelissen (2016). 
of the magnitude of peer effects across sectors provides new evidence on what drives these effects, whether social pressure or knowledge spillover.

In addition, unlike the extant studies, our analysis focuses on peer effects in wages rather than productivity, thereby addressing for the first time whether or not workers are rewarded for a peer-induced productivity increase through wages. To do so, we first develop a simple theoretical framework in which peer-induced productivity effects arise because of both social pressure and knowledge spillover and translate into peer-related wage effects even when the firm extracts the entire surplus of the match. The rationale underlying this result is that, if a firm wants to ensure that workers remain with the company and exert profit-maximizing effort, it must compensate them for the extra disutility from exercising additional effort because of knowledge spillover or peer pressure.

In the subsequent empirical analysis, we then estimate the effect of the long-term or predetermined quality of a worker's current peers - measured by the average wage fixed effect of coworkers in the same occupation and workplace (which we will refer to as "firms" for brevity) - on the current wage, a formulation that directly corresponds to our theoretical model. We implement this approach using an algorithm developed by Arcidiacono, Foster, Goodpaster and Kinsler (2012), which allows simultaneous estimation of both individual and peer group fixed effects. Because we link a worker's wage to predetermined characteristics (i.e., the peers' average worker fixed effect) rather than to peer group wages or effort, we avoid Manski's (1993) reflection problem.

To deal with worker sorting (i.e., the fact that high quality workers may sort into high quality peer groups or firms), we extend the worker and firm fixed effects model pioneered by Abowd et al. (1999) and estimated in for instance Card, Heining and Kline (2013) and condition on an extensive set of fixed effects. First, by including worker fixed effects in our baseline 
specification, we account for the potential sorting of high ability workers into high ability peer groups. In addition, to account for the potential sorting of high ability workers into firms, occupations, or firm-occupation combinations that pay high wages, we include firm-byoccupation fixed effects. To address the possibility that firms may attract better workers and raise wages at the same time, we further include time-varying firm fixed effects (as well as timevarying occupation fixed effects). As argued in Section 2.1, this identification strategy is far tighter than most strategies used to estimate peer effects in other settings.

On average, we find only small, albeit precisely estimated, peer effects in wages: a one standard deviation increase in peer ability increases wages by 0.3 percentage points. Even if peer effects are small on average for a representative set of occupations, they might still be substantial for specific occupations. In fact, the specific occupations and tasks analyzed in the existent studies on peer pressure (i.e., supermarket cashiers, data entry workers, envelope stuffers, fruit pickers) are occupations in which there is more opportunity for coworkers to observe each other's output, a prerequisite for peer pressure build-up. Similarly, the specific occupations and tasks analyzed in the studies on knowledge spillover (i.e., scientists, teachers) are high skilled and knowledge intensive, making learning from coworkers particularly important.

In a second analytical step, therefore, we restrict our analysis to occupations similar to those studied in that literature. Nevertheless, in line with Waldinger (2012), in occupations for which we expect knowledge spillover to be important (i.e., occupations that are particularly innovative and demand high skills), we again find only small peer effects in wages. On the other hand, in occupations where peer pressure tends to be more important (i.e., where the simple repetitive nature of the tasks makes output more easily observable to coworkers), we find larger peer effects. In these occupations, a $10 \%$ increase in peer ability increases wages by $0.6-0.9 \%$. Not only are these findings remarkably robust to a battery of robustness checks, but we provide 
several types of additional evidence for social pressure being their primary source. In comparison, Mas and Moretti (2009) and Falk and Ichino (2006), studying peer effects in productivity (rather than in wages) in one large supermarket chain and in a controlled laboratory experiment, find effects that are about twice as large. This difference may be because of productivity increases not translating one for one into wage increases.

Our results are important for several reasons. First, our finding of only small peer effects in wages on average suggests that the larger peer effects established in specific settings in existing studies may not carry over to the labor market in general. Overall, therefore, our results suggest that peer effects do not contribute much to inequality in the economy. ${ }^{3}$ Second, even though our results suggest that the findings of earlier studies cannot be extended to the entire labor market, they do indicate that they can be generalized beyond the single firm or single occupation on which they are based. That is, our findings highlight larger peer effects in low skilled occupations in which coworkers can, because of the repetitive nature of the tasks performed, easily judge each other's output—which are exactly the type of occupations most often analyzed in earlier studies on peer pressure. Our findings also add to the existing studies by showing that in such situations, peer effects lead not only to productivity spillover but also to wage spillover, as yet an unexplored topic in the literature.

The remainder of the paper is structured as follows. The next section outlines a theoretical framework that links peer effects in productivity engendered by social pressure and knowledge spillover to peer effects in wages. It also clarifies the interpretation of the peer effect identified in the empirical analysis. Sections 2 and 3 then describe our identification strategy and our data, respectively. Section 4 reports our results, and Section 5 summarizes our findings.

\footnotetext{
${ }^{3}$ Our general result of no strong peer effects within firms is in line with a recent paper by Bloom et al. (2013), who show that workers who work from home are somewhat more productive than those who come in to work.
} 


\section{Theoretical Framework}

To motivate our empirical analysis, we develop a simple principal-agent model of unobserved worker effort in which peer effects in productivity translate into peer effects in wages, and model two channels: knowledge spillover and social pressure. Here, we focus on the basics of the model, and delegate details to Online Appendix A.

\subsection{Basic Model}

\section{Production Function and Knowledge Spillover}

Consider a firm that employs $\mathrm{N}$ workers. In the theoretical analysis, we abstract from the endogenous sorting of workers into firms, which our empirical analysis takes into account. We next suppose that worker i produces individual output $f_{i}$ according to the following production function:

$$
f_{i}=y_{i}+\varepsilon_{i}=a_{i}+e_{i}\left(1+\lambda^{K} \bar{a}_{\sim i}\right)+\varepsilon_{i},
$$

where $y_{i}$ is the systematic component of worker $i$ 's productive capacity, depending on individual ability $a_{i}$, individual effort $e_{i}$ and average peer ability (excluding worker i) $\bar{a}_{\sim i}$. In this production function, individual effort and peer ability are complements, meaning that workers benefit from better peers only if they themselves expend effort. In other words, the return to effort is increasing in peer ability, and the greater this increase, the more important the knowledge spillover captured by the parameter $\lambda^{K}{ }^{4}$ The component $\varepsilon_{i}$ is a random variable reflecting output variation that is beyond the workers' control and has an expected mean of zero.

\footnotetext{
${ }^{4}$ It should be noted that, just as in extant studies, this formulation abstracts from the dynamic implications of knowledge spillover, and is best interpreted as one of contemporaneous knowledge spillover through assistance and cooperation between workers on the job. The underlying rationale is that workers with better peers are more productive on the job because they receive more helpful advice from their coworkers than if they were in a lowquality peer group. Moreover, although a high quality coworker may still boost a worker's productivity even when the two are no longer working together, one would still expect current peers to be more important than past peers. In addition, this specification assumes that own effort and time is required to 'unlock' the potential of one's peers' ability. This assumption of complementarity between knowledge spillover and effort provision is one of the drivers of why knowledge spillover translates into wages in our model: workers exposed to better peers exert higher effort, for which they have to be compensated in terms of higher wages.
} 
Firm productivity simply equals the sum of worker outputs. Whereas a worker's ability is exogenously given and observed by all parties, effort is an endogenous choice variable. As is standard in the principal agent literature, we assume that the firm cannot separately observe either worker effort $e_{i}$ or random productivity shocks $\varepsilon_{i}$.

\section{Cost of Effort and Social Pressure}

Because exerting effort is costly to the worker, we assume that in the absence of peer pressure, the cost of effort function is quadratic in effort: $C\left(e_{i}\right)=k e_{i}^{2}$. As in Barron and Gjerde (1997), Kandel and Lazear (1992), and Mas and Moretti (2009), we introduce peer pressure by augmenting the individual cost of effort function $C($.$) with a social "peer pressure" function \mathrm{P}($. that depends on individual effort $e_{i}$ and average peer output $\bar{f}_{\sim i}$ (excluding worker i). We propose a particularly simple functional form for the peer pressure function: $P\left(e_{i}, \bar{f}_{\sim i}\right)=$ $\lambda^{P}\left(m-e_{i}\right) \bar{f}_{\sim i}$, where $\lambda^{P}$ and $m$ can be thought of as both the "strength" and the "pain" from peer pressure. The total disutility associated with effort thus becomes

$$
c_{i}=C\left(e_{i}\right)+P\left(e_{i}, \bar{f}_{\sim i}\right)=k e_{i}^{2}+\lambda^{P}\left(m-e_{i}\right) \bar{f}_{\sim i} .
$$

Although the exact expressions derived in this section depend on the specific functional form for the total disutility associated with effort, our general argument does not. This peer pressure function implies that the marginal cost of worker effort is declining in peer output (i.e.,

$\left.\frac{\partial^{2} P\left(e_{i}, \bar{f}_{\sim i}\right)}{\partial e_{i} \partial \bar{f}_{\sim i}}=-\lambda^{P}<0\right)$. This condition implies that it is less costly to exert an additional unit of effort when the quality of one's peers is high than when it is low. We further assume that, like Barron and Gjerde (1997), workers dislike working in a high-pressure environment—which amounts to imposing a lower bound on the parameter m (capturing the "pain from peers") in the peer pressure function $\mathrm{P}($.$) (see Online Appendix A.1 for details).$ 


\section{Wage Contracts and Worker Preferences}

Firms choose a wage contract that provides their workers with the proper incentives to exert effort. Because the firm cannot disentangle $e_{i}$ and $\varepsilon_{i}$, however, it cannot contract a worker's effort directly but must instead contract output $f_{i}$. As is typical in the related literature, we restrict the analysis to linear wage contracts. Contrary to the standard principal agent model, we assume that not only firms but also workers are risk neutral, an assumption that simplifies our analysis without being a necessary condition for our general argument.

\subsection{The Worker's Maximization Problem}

Because of risk neutrality, workers maximize their expected wage minus the combined cost of effort. As shown in Online Appendix A.2, this leads to the first order condition

$$
e_{i}=\frac{\lambda^{P}}{2 k} \bar{e}_{\sim i}+\frac{b}{2 k}+\frac{\lambda^{P}+b \lambda^{K}}{2 k} \bar{a}_{\sim i} \quad \text { for } i=1, \ldots, N
$$

where $b$ denotes the slope of the wage contract with respect to worker output. This first order condition not only highlights that equilibrium effort is increasing in peer ability (see last term), either because of peer pressure $\lambda^{P}$ or knowledge spillover $\lambda^{K}$, but also that peer pressure $\left(\lambda^{P}>0\right)$ leads to a social multiplier effect whereby the more effort exerted by peers, the more effort exerted by the worker $\left(e_{i}\right.$ is increasing in $\left.\bar{e}_{\sim i}\right)$.

\subsection{The Firm's Optimization Problem}

Firms choose the intercept and slope (or incentive) parameter of the wage contract by maximizing expected profits, $E P=\sum_{i} E\left[f_{i}-w_{i}\right]$, taking into account the workers' optimal effort levels $e_{i}^{*}$, subject to the participation constraint that workers receive a utility that is at least as high as the outside option $v\left(a_{i}\right): E U_{i} \geq v\left(a_{i}\right)$. Assuming that the participation constraint holds with equality so that the firm pushes the worker's wage to her reservation utility, the firm 
ultimately rewards the worker for the outside option $v\left(a_{i}\right)$, the cost of effort $C\left(e_{i}^{*}\right)$, and the disutility from peer pressure $P\left(e_{i}^{*}, \bar{y}_{\sim i}\right)$ :

$$
E w_{i}=v\left(a_{i}\right)+C\left(e_{i}^{*}\right)+P\left(e_{i}^{*}, \bar{y}_{\sim i}\right),
$$

We can then derive the firm's first order condition and an expression for the slope $b^{*}$ of the optimal wage contract as detailed in Online Appendix A.3.

\subsection{The Effect of Peer Quality on Wages}

We obtain the average effect of peer ability on wages - our parameter of interest in the empirical analysis - by differentiating equation (2) and taking averages:

$$
\frac{1}{N} \sum_{i} \frac{d E w_{i}}{d \bar{a}_{\sim i}}=\underbrace{\frac{1}{N} \sum_{i} b^{*} \frac{\partial f_{i}}{\partial e_{i}} \frac{d e_{i}^{*}}{d \bar{a}_{\sim i}}}_{\begin{array}{c}
\text { Wage response to } \\
\text { own effort increase }
\end{array}}+\underbrace{\frac{1}{N} \sum_{i} \frac{\partial P\left(e_{i}, \bar{y}_{\sim i}\right)}{\partial \bar{y}_{\sim i}} \frac{d \bar{y}_{\sim i}}{d \bar{a}_{\sim i}}}_{\begin{array}{c}
\text { Wage response to disutility } \\
\text { from social pressure }
\end{array}}
$$

where all terms are evaluated at optimal effort levels and at the optimal $b$. The first term captures the wage response to the increase in workers' own effort and consists of three parts which are all positive: the slope of the wage contract, $b^{*}$, the marginal effect of effort on

productivity, $\frac{\partial f_{i}}{\partial e_{i}}$, and the effect of peer ability on equilibrium effort, $\frac{d e_{i}^{*}}{d \bar{a}_{\sim i}}$ (see equation (1)). The second term is likewise positive and captures that higher peer ability is associated with higher peer output $\left(\frac{d \bar{y}_{\sim i}}{d \bar{a}_{\sim i}}>0\right)$, which causes additional "pain" from peer pressure $\left(\frac{\partial P\left(e_{i}, \bar{y}_{\sim i}\right)}{\partial \bar{y}_{\sim i}}>0\right)$ for which the worker has to be compensated. Our model thus predicts that the average effect of peer ability on wages will be unambiguously positive-because better peers induce the worker to exert more effort and to work under pressure, for which the firm has to compensate the worker.

\section{Empirical Implementation}

In our empirical analysis, we seek to estimate the average effect of peer ability on wages as derived in equation (3). While in the model above we abstract from worker sorting, our empirical 
analysis needs to take account of non-random allocation of workers to firms and unobserved background characteristics. As we describe in detail below, to deal with worker sorting, our baseline empirical strategy extends the worker and firm fixed effects model pioneered by Abowd et al. (1999) and conditions on an extensive set of fixed effects. We define a worker's peer group as all workers working in the same (3-digit) occupation and in the same firm in period $\mathrm{t}$ (see Section 3.2 for a detailed discussion of the peer group definition).

\subsection{Baseline Specification and Identification}

First, we estimate the following baseline wage equation:

$$
\ln w_{i o j t}=a_{i}+\gamma \bar{a}_{\sim i, o j t}+x_{i o j t}^{\prime} \beta+\omega_{o t}+\delta_{j t}+\theta_{o j}+v_{i o j t}
$$

Here $\ln w_{i o j t}$ is the individual log real wage, $x_{i o j t}$ is a vector of time-varying characteristics with an associated coefficient vector $\beta$, i indexes workers, o indexes occupations, $\mathrm{j}$ indexes workplaces or production sites (which we label "firms" for simplicity), $t$ indexes time periods, and $a_{i}$ is a worker fixed effect. The term $\bar{a}_{\sim i, o j t}$ corresponds to $\bar{a}_{\sim i}$ in the theoretical model, and is the average worker fixed effect in the peer group, computed by excluding individual $i$. The coefficient $\gamma$ is the parameter of interest and measures (a positive monotone transformation of) the spillover effect in wages $\left(\frac{1}{N} \sum_{i} \frac{d E w_{i}}{d \bar{a}_{\sim i}}\right.$ in equation (3) which embodies not only the direct effect of peer ability on wages, holding peer effort constant, but also the social multiplier effect arising from workers' effort reactions in response to increases in the current effort of their peers. ${ }^{5}$ Identifying this reduced-form or total effect of peers' long-term productivity on wages requires conditioning on $\bar{a}_{\sim i, o j t}$ as a measure of the peers' long-term productivity (a predetermined

\footnotetext{
${ }^{5}$ It should be noted that the theoretical wage equation in (3) refers to wage levels, whereas the empirical wage equation in (4) is estimated in logs. Since the logarithm is a positive monotone transformation, the key prediction of our model carries over to log wages: In the presence of knowledge spillover or peer pressure, both wage levels and $\log$ wages are increasing in peer ability (i.e., $\gamma>0$ ).
} 
characteristic), but not conditioning on contemporaneous peer effort or productivity (or as a proxy thereof, peers' current wages). ${ }^{6}$

Nonetheless, identifying the causal peer effect $\gamma$ is challenging because of confounding factors such as shared background characteristics. Here, we first discuss the conditions required for a causal interpretation of the peer effect $\gamma$ assuming that $a_{i}$ and $\bar{a}_{\sim i, o j t}$ in equation (4) are observed. Then, in Section 2.3, we outline the issues arising from the fact that $a_{i}$ and $\bar{a}_{\sim i, o j t}$ are unobserved and must be estimated. While we are confident that our estimation strategy results in unbiased estimates of the effect of peer quality on wages, we will argue that any possible remaining bias is likely to be upward, so that our estimates are upper bounds of peer effects.

Peer quality may affect a worker's wage simply because high quality workers sort into high quality peer groups or high quality firms, leading to a spurious correlation between peer quality and wages. Our estimation strategy accounts for the endogenous sorting of workers into peer groups or firms by including control variables and multiple fixed effects. First, because our baseline specification in equation (4) includes worker fixed effects, it accounts for the potential sorting of high ability workers into high ability peer groups. ${ }^{7}$ Second, time-varying occupation effects $\omega_{o t}$ are included to capture diverging time trends in occupational pay differentials. Moreover, our inclusion of time-varying firm fixed effects $\delta_{j t}$ controls for shocks that are firm specific. Finally, by controlling for firm specific occupation effects $\theta_{o j}$, we allow for the possibility that a firm may pay specific occupations relatively well (or badly) compared to the market.

Estimation of $\gamma$ in equation (4) exploits two sources of variation: changes in peer quality for workers who switch peer groups (after having controlled for the accompanying changes in firm

\footnotetext{
${ }^{6}$ Therefore, there is no reflection problem in estimating the peer effect $\gamma$ in equation (4) Manski, 1993).

${ }^{7}$ Since $x_{\text {iojt }}$ in equation (4) includes quadratics in age and firm tenure, the worker fixed effects are net of age and job tenure, and the average peer fixed effect does not capture effects of peer age or peer job tenure.
} 
and occupation specific fixed effects), and changes in peer quality for workers who remain with their peer group, induced by other workers joining or leaving the peer group. Focusing on the latter source of variation, our identification strategy can essentially be understood as a difference-in-difference estimator. To see this, denote by $\tilde{a}_{\text {iojt }}$ the peer group quality purged from effects of observables $\left(x_{\text {iojt }}\right)$ and occupation-specific shocks common to all firms in the economy $\left(\omega_{o t}\right){ }^{8}$ Suppose further for simplicity that all firms consist of two occupations only, denoted by o and o'. First differencing of equation (4) for peer group stayers eliminates the time-constant worker and firm-occupation fixed effects $a_{i}$ and $\theta_{o j}$-and more generally any time-constant effects such as a match-specific effects $\mathrm{m}_{i o j}$ - but does not remove the firmspecific shock common to all occupations in the firm $\left(\Delta \delta_{j t}\right): \Delta \ln w_{i o j t}=\gamma \Delta \tilde{a}_{\text {iojt }}+\Delta \delta_{j t}+\Delta v_{i o j t}$. This effect can be eliminated through differencing a second time, between occupations o and o' in the same firm that experienced different changes in peer quality:

$$
\underbrace{\underbrace{\Delta \overline{\ln w_{o j t}^{\mathrm{s}}}}_{\text {first difference }}-\Delta \overline{\ln w_{o^{\prime} j t}^{\mathrm{s}}}}_{\text {second difference }}=\gamma\left(\Delta \overline{\tilde{\tilde{a}}}_{o j t}^{\mathrm{s}}-\Delta \overline{\tilde{\tilde{a}}}_{o^{\prime} j t}^{\mathrm{s}}\right)+\left(\Delta \bar{v}_{o j t}^{\mathrm{s}}-\Delta \bar{v}_{o \prime j t}^{\mathrm{s}}\right) .
$$

This firm-level regression consistently estimates $\gamma$ provided that $\operatorname{Cov}\left(\Delta \overline{\tilde{a}}_{o j t}^{\mathrm{s}}-\Delta \overline{\tilde{a}}_{o, j t}^{\mathrm{s}}, \Delta \bar{v}_{o j t}^{\mathrm{s}}-\right.$ $\left.\Delta \bar{v}_{o^{\prime} j t}^{\mathrm{s}}\right)=0$. This condition says that peer group stayers in both occupations in the firm experience the same time shock, which corresponds to the standard common time trend assumption in difference-in-difference estimation.

Our identification assumptions are considerably weaker than the assumptions typically invoked in the education literature, which seek to identify exogenous spillover effects (e.g., the impact of the share of girls, Blacks, immigrants, or grade repeaters on individual performance). The most common approach in these studies-measuring grade-level peer characteristics and

\footnotetext{
${ }^{8}$ That is, $\tilde{a}_{\text {iojt }}$ is the residual from the regression of $\bar{a}_{\sim i, o j t}$ on $x_{i o j t}$ and $\omega_{o t}$.
} 
exploiting within-school variation over time (e.g., Gould, Lavy, and Paserman, 2009; Hanushek et al., 2003; Hoxby, 2000; Lavy and Schlosser, 2011; Lavy, Paserman, and Schlosser, 2012)— does not allow for the possibility that the average quality of students (in our case, workers) in the school (firm) changes over time, or that the school's effect on student performance (wages) may vary over time. Other research employs an alternative approach: measuring peer characteristics at the classroom level and exploiting within-school grade-year variation (e.g., Ammermueller and Pischke, 2009; Betts and Zau, 2004; McEwan, 2003; Vigdor and Nechyba, 2007). This technique, however, requires random assignment of students into classrooms within the school (equivalent to occupations within a firm), thereby ruling out within-school student tracking. Our analysis, in contrast, can account for nonrandom selection into occupations within firms by including firm-specific occupation effects.

\subsection{Within-Peer Group Estimator}

One remaining concern may be the possible presence of time-varying peer group-specific wage shocks that are correlated with shocks to peer group quality, violating the common time trend assumption highlighted above. The existence of such shocks is likely to lead to an upward bias. For example, a firm may adopt a new technology specific to one occupation only, simultaneously raising wages and worker quality in that occupation relative to other occupations in the firm, implying that $\operatorname{Cov}\left(\Delta \overline{\tilde{a}}_{o j t}^{\mathrm{s}}-\Delta \overline{\tilde{a}}_{o \prime j t}^{\mathrm{s}}, \Delta \bar{v}_{o j t}^{\mathrm{s}}-\Delta \bar{v}_{o \prime j t}^{\mathrm{s}}\right)>0$.

One way to deal with this problem is to condition on the full set of time-varying peer group fixed effects $p_{o j t}$. Note that the parameter $\gamma$ remains identified because focal worker $\mathrm{i}$ is excluded from the average peer group quality. As a result, the average peer group quality of the same group of workers differs for each worker, and $\bar{a}_{\sim i, o j t}$ differs for each worker within a peer 
group at any given point in time. Using only within-peer group variation for identification yields the following estimation equation: ${ }^{9}$

$$
\ln w_{i o j t}=a_{i}+\gamma \bar{a}_{\sim i, o j t}+x_{i o j t}^{T} \beta+p_{o j t}+\varepsilon_{i o j t}
$$

This within-peer group estimator, however, although it effectively deals with unobserved timevarying peer group characteristics, employs only limited and specific variation in $\bar{a}_{\sim i, o j t}$. That is, as shown in Online Appendix B, the spillover effect in equation (6) is identified only if peer groups vary in size. The advantage of being able to control for time-varying shocks to the peer group is thus countered by the disadvantage that only one particular type of variation is used to identify the effect. The within-peer group estimator in equation (6), therefore, serves as a robustness check only, rather than as our main specification.

\subsection{Estimation}

Whereas our discussion so far assumes that the individual and average worker fixed effects $a_{i}$ and $\bar{a}_{\sim i, o j t}$ are observed, they are in fact unobserved and must be estimated. The multiplication of $\bar{a}_{\sim i, o j t}$ and $\gamma$, both parameters to be estimated, turns equations (4) and (6) into nonlinear least squares problems. Because the fixed effects are high dimensional (i.e., we have approximately 600,000 firm years, 200,000 occupation-firm combinations, and 2,100,000 workers), using standard nonlinear least squares routines to solve the problem is infeasible. Rather, we adopt the alternative estimation procedure suggested by Arcidiacono, Foster, Goodpaster and Kinsler (2012), which is detailed in Online Appendix C. An appealing characteristic of this estimation procedure is that the nonlinear least squares estimator for $\gamma$ is consistent as the sample size grows in panels with a limited number of time periods, even though the individual worker fixed effects $a_{i}$ are generally inconsistent in this situation. This result,

\footnotetext{
${ }^{9}$ Because the fixed effects $\delta_{j t}, \omega_{o t}$ and $\theta_{o j}$ do not vary within peer groups at any given point in time, they are absorbed by $p_{\text {ojt }}$.
} 
however, requires further assumptions in addition to those we discussed above for the case when $a_{i}$ and $\bar{a}_{\sim i, o j t}$ are observed (see Theorem 1 in Arcidiacono, Foster, Goodpaster and Kinsler, 2012). Most importantly, the error terms between any two observations $\left(v_{\text {iojt }}\right.$ in our equation (4) baseline specification and $\varepsilon_{i o j t}$ in our equation (6) within-peer group estimator) must be uncorrelated. This assumption not only rules out serially correlated wage shocks, but also, in our baseline regression, any wage shocks common to the peer group, even those uncorrelated with peer group quality. This additional assumption is necessary for consistent estimation when $a_{i}$ and $\bar{a}_{\sim i, o j t}$ are unobserved because peer group-specific wage shocks affect not only peer group member wages but also estimated fixed effects in panels with a short T. Any such impact could lead to a spurious correlation between individual wages and the estimated worker fixed effects in the peer group even when the peer group-specific wage shocks are uncorrelated with the true worker fixed effects in the peer group.

Results from a Monte Carlo study discussed in Online Appendix F.1 show that while serial correlation of a plausible magnitude hardly biases peer effect estimates in our application, timevarying random peer group level shocks are likely to lead to an upward bias in panels with short T. However, under realistic assumptions the bias is not large enough to spuriously generate the level of peer effects that we find in low skilled repetitive occupations. Moreover, results from the Monte Carlo study confirm that even if time-varying peer group shocks were present, the withinpeer group estimator of equation (6) deals directly with the bias problem-as it conditions on peer-group level wage shocks.

\section{Data}

Our data set comes from over three decades of German social security records that cover every man and woman in the system observed on June 30 of each year. This data set is 
particularly suited for the analytical purpose because it includes identifiers for single production sites or workplaces (referred to as "firms" for simplicity), as well as detailed occupational codes that distinguish 331 occupations. Such detail allows us to define peer groups of coworkers in the same firm who are likely to interact. We can also observe all workers in each firm, which allows precise calculation of the average peer group characteristics and ensures that our findings are representative of both the firms and the workers.

\subsection{Sample Selection}

Focusing on the years 1989-2005, we select all workers aged between 16 and 65 in one large metropolitan labor market, the city of Munich and its surrounding districts. ${ }^{10}$ Because most workers who change jobs remain in their local labor market, concentrating on one large metropolitan labor market rather than a random sample of workers ensures that our sample captures most worker mobility between firms, which is important for our identification strategy of estimating firm and worker fixed effects. Since only the fixed effects within a group of firms connected by worker mobility are identified relative to each other, we restrict our sample to the biggest connected mobility group (which makes up $99.5 \%$ of the initial sample; see Section 4.5 for more details). ${ }^{11}$

Because the wages of part-time workers and apprentices cannot be meaningfully compared to those of regular full-time workers, we base our estimations on full-time workers not in apprenticeship. Additionally, to ensure that every worker is matched with at least one peer, we drop peer groups (firm-occupation-year combinations) with only one worker.

${ }^{10}$ We focus on the large metropolitan labor market rather than Germany as a whole in order to reduce the computational burden, which is far higher than in conventional linear worker and firm fixed effects models (as in e.g. Card et al., 2013), due to the inclusion of average peer quality in addition to firm-by-time and firm-by occupation-effects. Robustness checks we provide below and comparisons between the Munich area and Germany as a whole discussed in Online Appendix F.2 suggest that results for the whole of Germany would not be very different.

${ }^{11}$ Two firms are directly connected if worker mobility is observed between them in any sample period. A "connected mobility group" is the group of firms that are either directly or indirectly (via other firms) connected. 


\subsection{Definition of the Peer Group}

We define the worker's peer group as all workers employed in the same firm and the same 3digit occupation, the smallest occupation level available in the social security data. These include detailed occupational definitions such as bricklayers, florists, plumbers, pharmacists, and high school teachers. Defining the peer group at the 3-digit (as opposed to the 1- or 2-digit) occupation level not only ensures that workers in the same peer group are likely to interact with each other, a prerequisite for knowledge spillover, but also that workers in the same peer group perform similar tasks and are thus likely to judge each other's output, a prerequisite for peer pressure build-up. Occupations at the 2-digit level, in contrast, often lump together rather different occupations. For example, the 3-digit occupation of a cashier is part of the same 2-digit occupation as accountants and computer and data processing consultants. In Online Appendix D, we show that defining the peer group as too large or too small is likely to lead to attenuation bias of the true peer effect. However, the robustness and placebo tests in Tables 6 and 7 suggest that our peer group definition at the 3-digit occupation level is the most plausible.

\subsection{Isolating Occupations with High Levels of Peer Pressure and Knowledge Spillover}

One important precondition for the build-up of peer pressure is that workers can mutually observe and judge each other's output, an evaluation facilitated when tasks are relatively simple and standardized but more difficult when job duties are diverse and complex. To identify occupations characterized by more standardized tasks, for which we expect peer pressure to be important, we rely on a further data source, the 1991/92 wave of the Qualification and Career Survey (see Gathmann and Schönberg, 2010, for a detailed description). In addition to detailed questions on task usage, respondents are asked how frequently they perform repetitive tasks and tasks that are predefined in detail. From the answers, we generate a combined score on which to rank occupations. We then choose the set of occupations with the highest incidence of repetitive 
and predefined tasks, which encompasses $5 \%$ of the workers in our sample (see column (1) of Online Appendix Table F.3 for a full list of the occupations in this group). This group of most repetitive occupations includes agricultural workers, the subject of the Bandiera et al. (2010) study, and cashiers, the focus of the Mas and Moretti (2009) study. The remaining occupations are mostly low skilled manual occupations, such as unskilled laborers, packagers, or metal workers.

For robustness, we also estimate peer effects for the exact same occupations as in the extant studies using real-world data-that is, cashiers (Mas and Moretti, 2009), agricultural helpers (Bandiera et al., 2010), and data entry workers (Kaur et al., 2010)—as well as for a handpicked set of low skilled occupations in which, after initial induction, on-the-job learning is limited. This subgroup, which includes waiters, cashiers, agricultural helpers, vehicle cleaners, and packagers among others, makes up $14 \%$ of the total sample (see column (2) of Online Appendix Table F.3 for a full list). Unlike the 5\% most repetitive occupations, this group excludes specialized skill craft occupations in which learning may be important, such as ceramic workers or pattern makers.

To isolate occupations in which we expect high knowledge spillover, we select the $10 \%$ most skilled occupations in terms of workers' educational attainment (average share of university graduates), which includes not only the scientists, academics, and teachers used in previous studies, but also professionals such as architects and physicians. As a robustness check, we also construct a combined index based on two additional items in the Qualification and Career Survey: whether individuals need to learn new tasks and think anew, and whether they need to experiment and try out new ideas. From this index, we derive the $10 \%$ of occupations with the highest scores, which again includes scientists and academics but also musicians and IT specialists. We further handpick a group of occupations that appear very knowledge intensive, 
including doctors, lawyers, scientists, teachers, and academics (see columns (3) to (5) of Online Appendix Table F.3 for a full list of occupations in these three groups).

It should be noted that when focusing on occupational subgroups, we still estimate the model on the full sample and allow the peer effect to differ for both the respective subgroups and the remaining occupations. Doing so ensures that we use all information available for firms and workers, which makes the estimated firm-year and worker fixed effects - and hence the measure for average peer quality—more reliable.

\subsection{Wage Censoring}

As is common in social security data, wages in our database are right censored at the social security contribution ceiling. Such censoring, although it affects only $0.7 \%$ of the wage observations in the $5 \%$ most repetitive occupations, is high in occupations with high expected knowledge spillover. We therefore impute top-coded wages using a procedure similar to that employed by Dustmann et al. (2009) and Card et al. (2013) (see Online Appendix E for details). Whether or not we impute wages, however, our results remain similar even in the high skilled occupations with high censoring. This finding is not surprising given that censoring generally causes the distributions of both worker fixed effects and average peer quality to be compressed in the same way as the dependent variable, meaning that censoring need not lead to a large bias in the estimated peer effect.

\subsection{Descriptive Statistics}

In Table 1, we compare the 5\% most repetitive occupations, in which we expect particularly high peer pressure, and the $10 \%$ most skilled occupations, in which we expect high knowledge spillover, against all occupations in our sample. Clearly, the 5\% most repetitive occupations are low skilled occupations: nearly half $(47 \%)$ the workers have no post-secondary education 
(compared to $17 \%$ in the full sample and $4 \%$ in the skilled occupations sample) and virtually no worker has graduated from a college or university (compared to $18 \%$ in the full sample and $80 \%$ in the skilled occupations sample). As expected, the learning content in the $5 \%$ most repetitive occupations is low, while it is high in the $10 \%$ most skilled occupations, as implied by responses to whether individuals need to learn new tasks or to experiment with new ideas. The median peer group size of 3 or 4 workers per peer group is similar in all three samples. Not surprisingly, peer group size is heavily skewed, with the mean peer group size exceeding the median peer group size by a factor of about 3-4 in the three samples.

To identify peer effects in wages, individual wages must be flexible enough to react to peer quality induced changes in productivity. The evidence presented in Figure 1 and the bottom half of Table 1 illustrates that despite relatively high collective bargaining coverage rates in Germany, there is substantial wage variation across coworkers in the same occupation and firm. ${ }^{12}$ First, the within-peer group standard deviation of the log wage residuals (obtained from a regression of log wages on quadratics in age and firm tenure and aggregate time trends) accounts for a considerable share of the overall standard deviation: about half in the full sample (0.24 vs. $0.47)$, about two thirds in the $5 \%$ most repetitive occupations sample ( 0.20 vs. 0.33 , and about three quarters in the $10 \%$ most skilled occupations sample (0.27 vs. 0.37$)$. Second, real wages are downwardly flexible: about $9 \%$ of peer-group stayers in the full sample, $3 \%$ in the skilled occupations sample, and $13 \%$ in the repetitive occupations sample experience a real wage cut from one year to another of at least 5\%. Third, as the figures in the last row of Table 1 illustrate,

${ }^{12}$ Collective bargaining agreements in Germany allow for substantial real wage flexibility. First, nothing prevents firms from paying wages above the level stipulated by collective agreements, or to pay extra bonuses based on performance. About $90 \%$ of workers receive some form of wage supplement on top of their wage base (own calculations based on the German Socio-Economic Panel, 1994-2006). Second, wages are usually tied to job titles, not to occupations. Hence within occupations in the same firm, there can be different ranks of job titles into which workers can be promoted based on their productivity. Third, collectively bargained wage floors are agreed in nominal terms, which allows for real-wage cuts by freezing nominal wages. 
average real wage growth over our sample period was positive and in the order of $2 \%$ per year, implying that decreases in productivity can be accommodated by raising wages more slowly rather than actually cutting nominal or real wages.

We provide additional information on the structure of our sample in Table 2. Our overall sample consists of 2,115,544 workers, 89,581 firms, and 1,387,216 peer groups; workers are observed on average for 6.1 time periods and there are 2.3 peer groups on average per firm and year. Separately identifying worker, firm-occupation and firm-time fixed effects requires worker mobility between occupations and firms. In our sample, workers have on average worked for 1.6 firms and in 1.4 different occupations. This amount of mobility is sufficient to identify firm-year and firm-occupation fixed effects for nearly the entire sample: the biggest connected groups for firm-time effects and firm-occupation fixed effects contain $99.4 \%$ and $98.3 \%$ of the original observations, respectively, compared to $99.5 \%$ for the more standard firm fixed effects. ${ }^{13}$

In our baseline specification based on equation (4), the standard deviation of the estimated worker fixed effects for the full sample $\left(a_{i}\right.$ in equation (4) 0.32 or $70 \%$ of the overall standard deviation of log wages. The average worker fixed effects in the peer group (excluding the focal worker $\bar{a}_{\sim i, o j t}$ in equation (4) has a standard deviation of 0.24 , which is about $50 \%$ of the overall standard deviation of the log wage.

As explained in Section 2.1, our baseline specification identifies the causal effect of peers on wages by exploiting two main sources of variation in peer quality: changes to the peer group make-up as workers join and leave the group, and moves to new peer groups by the focal worker. In Figure 2, we plot the kernel density estimates of the change in a worker's average peer quality from one year to the next separately for those who remain in the peer group (stayers) and those

\footnotetext{
${ }^{13}$ Note that all firm stayers are "movers" between firm-time units so that it is not surprising that the connected group is nearly as large for firm-by-time fixed effects as for the firm fixed effects. Further note that unlike standard firm-fixed effects, the firm-occupation fixed effects are identified not only through worker mobility across firms, but also through worker mobility between occupations within firms.
} 
who leave (movers). Not surprisingly, the standard deviation of the change in average peer quality is more than three times as high for peer group movers than for peer group stayers $(0.20$ vs. 0.06; see also Table 2). Yet even for workers who remain in their peer group, there is considerable variation in average peer quality from one year to the next, corresponding to roughly $20 \%$ of the overall variation in average peer quality. As expected, for peer group stayers, the kernel density has a mass point at zero, corresponding to stayers in peer groups that no worker joins or leaves. Nonetheless, peer groups without turnover are rare. In our sample, 90\% of observations are in peer groups with at least some worker turnover. At $20 \%$, the average peer group turnover in our sample, computed as 0.5 times the number of workers who join or leave divided by peer group size, is quite large and implies that nearly $20 \%$ of workers in the peer group are replaced every year.

At the bottom of the table, we report correlation coefficients between the various fixed effects in equation (4). In our sample, the individual worker fixed effect and the average fixed effect of the peer group are with a correlation coefficient of 0.64 strongly positively correlated. In line with Card, Heining and Kline (2013), we also find a positive correlation between the worker and the firm-time and firm-occupation fixed effects of 0.14 and 0.16 , respectively. These correlations illustrate the endogenous sorting of high-ability workers into high ability and high wage peer groups and underscore the need to account for sorting in our estimates.

\section{Results}

\subsection{Baseline results}

We report estimates for the impact of average peer quality, measured as the average worker fixed effect of coworkers in the peer group, on wages for the full sample in Table 3 . Each column of the table introduces additional control variables to account for shared background 
characteristics. In column (1), we control for the worker's own fixed effect ( $a_{i}$ in equation (4)), for quadratics in age and firm tenure (captured by $x_{\text {iojt }}$ in equation (4), and for time-varying occupation fixed effects $\left(\omega_{o t}\right.$ in equation (4), in addition to firm fixed effects. The coefficient of .148 implies that a $10 \%$ increase in peer quality increases wages by $1.48 \%$ - an estimate roughly similar in magnitude to those reported by Lengerman (2002) and Battisti (2013) in a related specification. While this specification accounts for the possibility that workers employed in highwage firms work with better peers, it does not allow for firms which overpay specific occupations relative to the market to attract better workers into these occupations. To deal with this type of worker sorting, we control in column (2) for firm-occupation fixed effects $\left(\left(\theta_{o j}\right.\right.$ in equation (4) instead of simple firm fixed effects. This specification produces a much smaller estimate: a $10 \%$ increase in peer quality now increases the individual wage by only $0.66 \%$. It does not yet filter out time-varying shocks at firm level common to all occupations in the firm. Such shocks turn out to be important: When adding time-varying firm fixed effects $\left(\delta_{j t}\right.$ in equation (4) in column (3), we find that a $10 \%$ increase in peer quality raises individual wages by merely $0.1 \%$. Translated into standard deviations, this outcome implies that a one standard deviation increase in peer ability increases wages by 0.3 percentage points or 0.6 percent of a standard deviation. This effect is about 10-15 times smaller than the effects previously identified for productivity among supermarket cashiers in a single firm (Mas and Moretti 2009) and students carrying out a simple task in an experiment (Falk and Ichino 2006) - which incidentally are very close to the average effect reported by Herbst and Mas (2015) from a larger range of studies mostly covering specific field or lab settings. Therefore, we do not confirm similarly large spillover effects in wages for a representative set of occupations and firms. 


\subsection{Effects for Occupational Subgroups}

\section{Repetitive Occupations}

Even if peer effects in wages are small on average for a representative set of occupations, they might still be substantial for specific occupations. Hence, in Panel A of Table 4, we report the results for the $5 \%$ of occupations with the most repetitive and predefined tasks, in which we expect particularly high peer pressure. These occupations also more closely resemble those used in earlier studies on peer pressure. The first three columns in the table refer to the baseline specification given by equation (4) and condition on occupation-year, firm-year, and firmoccupation fixed effects, meaning that they correspond to specification (3) in the previous table.

For these repetitive occupations, we find a substantially larger effect of peer quality on wages than in the full sample: a $10 \%$ increase in peer quality raises wages by $0.64 \%$ (see column (1)) compared to the effect of $0.1 \%$ in the full sample (see column (3) of Table 3). This outcome implies that a one standard deviation increase in peer quality increases the wage by $0.84 \%$, about half the size of the peer effects in coworker productivity identified by Mas and Moretti (2009) and Falk and Ichino (2006) and in the meta-analysis by Herbst and Mas (2015).

Column (2) of Panel A shows the peer effect for the three occupations used in earlier studies (agricultural helpers, cashiers and data entry workers), which is remarkably similar in magnitude to that for the $5 \%$ most repetitive occupations shown in column (1). Column (3) reports the results for the handpicked group of occupations in which we expect easily observable output and, following initial induction, limited on-the-job learning. The estimated effect for this occupational group is slightly smaller than that for the $5 \%$ most repetitive occupations sample but still about five times as large as the effect for the full occupational sample.

Column (4) reports estimates using the within-peer group estimator for the $5 \%$ most repetitive occupations (see equation (6) . As we point out above, this estimator is robust to 
unobserved time-varying peer group wage shocks that are correlated with shocks to true or estimated peer group quality. The estimated peer effects based on the within-peer group specification is very close to the effect derived in the respective baseline specification. This similarity in estimates corroborates that time-varying peer group-specific wage shocks are not important, and provides reassurance that we are picking up a true peer effect rather than a spurious correlation.

\section{High Skilled Occupations}

In Panel B of Table 4, we restrict the analysis to particularly high skilled and innovative occupations with a high scope for learning, in which we expect knowledge spillover to be important. Yet regardless of how we define high skilled occupations (columns (1) to (3)), and whether or not we exploit variation in peer ability within peer groups only (column (4)), peer effects in these groups are small and resemble those in the full sample. Overall, therefore, we identify sizeable peer effects in wages only in occupations characterized by standardized tasks and low learning content, which are exactly the occupations in which we expect peer pressure to matter and which closely resemble the specific occupations investigated in the extant studies on peer pressure.

By looking at the $5 \%$ most repetitive and the $10 \%$ most skilled occupations we have distinguished between the two extreme ends of the two indexes of repetitiveness and skill from which the definition of these groups was derived. In Figure 3 we show results from a more complete analysis that lets the peer effect coefficient vary by bins of these two indexes. They show a symmetric pattern, with highest peer effects in the most repetitive / least skilled categories, smallest peer effects in the middle categories, and again slightly higher but still small 
effects in the least repetitive / most skilled categories. ${ }^{14}$ The U-shape of the estimated peer effects in these indexes provides support for our hypothesis that peer pressure and knowledge spillover are two possible mechanism for peer effects, where the former operates predominantly in the most repetitive (and least skilled) occupations, while the latter is most pronounced in the least repetitive and most skilled occupations.

\subsection{Timing of Effects}

Figure 4 provides a first visual impression of the timing of the wage response to a change in peer quality in the $5 \%$ most repetitive occupations where peer effects are largest. Panels A and B show the evolutions of peer quality and residualized wages (purged of the observables and fixed effects included in equation (4)) of peer group stayers experiencing an exceptionally large rise or fall in peer quality (of at least 0.055 ), while Panel $\mathrm{C}$ depicts the corresponding evolutions for peer group movers experiencing an increase in peer quality (of at least 0.10 ). The figures illustrate that for both peer group stayers and movers, the increase (or decrease) in peer quality is accompanied by an immediate increase (or decrease) in wages in the same year, with little evidence for dynamic effects. $^{15}$

We analyze the timing of peer effects more systematically in Table 5, by including lags and leads of peer quality (computed from the estimated worker fixed effects from the baseline model). In column (1) of Table 5, we first augment our baseline model by adding the quality of a worker's peers in two future periods $(t+1$ and $t+2)$. The inclusion of future peer quality represents a placebo test, as workers cannot feel peer pressure or learn from colleagues whom

\footnotetext{
${ }^{14}$ The skill and repetitiveness indexes are strongly correlated with a correlation coefficient of -.76

${ }^{15}$ It should be noted that any visual illustration of the relationship between two continuously varying variables (peer quality and wages) in an event study graph will necessarily select the underlying sample and reduce the sample size. For instance, workers in the most repetitive occupations who have been with the same firm for at least five periods, and have experienced a rise in peer quality of at least .055 in period zero (the "event"), are more likely to be in small peer groups, because the average of peer quality is more variable in small groups and thus large rises are more common. It should therefore not be surprising if the graphical examples slightly deviate from the overall estimates that use the entire sample.
} 
they have not yet met. Reassuringly, we find that the effect of future peers is essentially zero in both repetitive (Panel A) and high skilled occupations (Panel B), whereas the effect of current peers remains of the same magnitude as in our baseline specification.

In column (2) of Table 5, we add the average worker fixed effects for the peer group lagged by one and two periods into our baseline regression. The effects of lagged peer quality are informative about the mechanisms for peer effects: If peer effects are generated by peer pressure, then past peers should be irrelevant conditional on current peers in that workers should feel peer pressure only from these latter. If, on the other hand, peer effects result from learning, both past and current peers should matter, since the skills learnt from a coworker should be valuable even after the worker or coworker has left the peer group. We find that in the repetitive sector, the average quality of lagged peers has almost no effect on current wages, suggesting that knowledge spillover is not the primary channel of the peer effects in that sector. Relative to the contemporaneous effect, the lagged effects are slightly more important in skilled occupations (columns (2) and (3) of Panel B Table 5), but overall effects continue to be very small. The general pattern of results that only contemporary peer quality matters does not change when including lags and leads jointly in column (3) of Table 5.

\subsection{Geographically and Economically Close Workers Outside of the Immediate Peer Group}

In Table 6, we further assess whether the quality of workers outside of the immediate peer group affects wages. While providing a test of whether our peer group definition is appropriate, the results also shed light on the potential channel of peer effects. In the case of peer pressure, the relevant peers are contemporaneous coworkers in the immediate peer group within the firm who frequently interact and carry out comparable tasks, as peer pressure can only build up if workers work alongside each other and can observe and compare each other's output. If, in contrast, peer 
effects result from knowledge spillover, a much wider group of peers is potentially relevant, since knowledge spillover is not restricted to occur within the firm only. In fact, knowledge spillover is often assumed to operate through interactions of workers who do not necessarily work in the same firm but are geographically or economically close (see, e.g., Lucas, 1988; Moretti, 2004).

In Panel A Table 6, we estimate the effects of the quality of workers in other occupations within the same firm on wages. In rows (i) and (ii) of Panel A, we randomly choose a 3-digit occupation (other than the worker's own occupation) in the same firm, and distinguish whether the randomly assigned occupation is economically close or far, as measured by observed worker flows between occupations in the overall sample. ${ }^{16}$ The results show that in both the repetitive and skilled sector, the quality of coworkers in other occupations within the same firm has virtually no impact on wages, no matter whether the occupation is close or far. We corroborate these findings in rows (iii) and (iv) of Panel A, where we display the impact on wages of the quality of workers in the economically closest and farthest occupation (relative to the focal worker's own occupation) in the same firm, again measuring economic closeness by observed worker flows between occupations in the overall sample. Overall, these findings provide strong evidence for the validity of defining the peer group as workers from the same 3-digit occupation in the same firm, and speak against knowledge spillover or peer pressure across occupations within the same firm.

In Panel B of Table 6, we augment our baseline model by adding the quality of workers in other firms that are economically close (in terms of worker flows) to the focal worker's peer group. First, we include the average peer fixed effect of workers who in year $t$ are in peer groups (firm-occupation combinations) in other firms that at any point during the observation period

\footnotetext{
${ }^{16}$ We define a pair of occupations as "close" if the proportion of workers switching between these occupations is above median, and "far" if it is below median.
} 
have exchanged workers with the focal worker's peer group. Second, we identify the peer groups from which new joiners to the focal peer group came (i.e., the peer groups in which the joiners were in t-1), and we add the average worker fixed effect of the workers who were in these peer groups in t-1 but who did not join the focal peer group (i.e., the joiners' past peers). Effects from these economically close workers in other firms are virtually zero, providing little evidence for knowledge spillover across peer groups in different firms linked by worker mobility.

In Panel $\mathrm{C}$ of Table 6 we augment our baseline model by adding the average fixed effect of all workers residing in the same municipality and working in the same occupation (but not necessarily in the same firm) as the focal worker. We find that peer quality in the municipality has no effect on wages, whereas the effect of peer quality in the firm remains unchanged.

In sum, the results in Table 6 provide little evidence of knowledge spillover or peer pressure from workers outside the immediate peer group. Rather, they suggest that peer effects in the repetitive sector are confined to the same 3-digit occupation and firm, as one would expect if peer pressure is the main driving force behind peer effects.

\subsection{Robustness Checks}

As Table 7 shows, estimated peer effects remain robust to a number of alternative specifications for both the repetitive (column (1)) and the high skilled sector (column (2)). As a point of reference, the row (i) replicates the results from the baseline specification of column (1), Table 4.

As illustrated in Figure 2, our baseline specification exploits two sources of variation in peer quality: changes to the peer group make-up as coworkers join and leave the group, and moves to new peer groups by the focal worker. Unlike the latter, the former controls for the presence of time-constant match-specific effects $\mathrm{m}_{i o j}$ that are correlated with peer ability (as first differencing eliminates these for peer group stayers, but not for peer group movers). Rows (ii) 
and (iii) show that both sources of variation lead to very similar peer effects, indicating that our baseline peer estimates are not biased because of match-specific shocks. ${ }^{17}$

In row (iv), we report results when the censored wage observations are not imputed. In row (v), we relax the assumption that observable characteristics have the same effects in repetitive occupations and high skilled occupations. In row (vi), we extend our estimation sample to include not only the metropolitan area of Munich, but also additional surrounding rural areas. In row (vii), we add to the regression the average observed characteristics (firm tenure, age, and schooling) of peers. In rows (viii) and (ix), we display peer effect estimates separately for small $(\leq 10)$ and large $(>100)$ peer groups. ${ }^{18}$ Remarkably, for both repetitive and high skilled occupations, all these different specifications yield similar estimates as the baseline estimates reported in Table 4.

The evidence presented in Panel A of Table 6 suggests that workers rarely interact with coworkers outside the same 3-digit occupation in the firm, supporting the definition of the peer group as workers from the same 3-digit occupation, rather than the same 2- or 1-digit occupation, in the same firm. In row (x) of Table 7, we display peer effect estimates for a narrower peer group definition where we split peer groups at the 3-digit occupational level further up into two age groups (above and below median age). Interestingly, the peer effect drops by more than 50\%, which is in line with the hypothesis that the exclusion of relevant peers from the peer group leads to an attenuation bias. Overall, this drop, in conjunction with the findings in Panel A of Table 6,

\footnotetext{
${ }^{17}$ This is in line with Card, Heining and Kline (2013) and Card, Cardoso and Kline (2014) who show that once firm fixed effects are accounted for, match-specific effects are not an important determinant of worker mobility.

${ }^{18}$ In Online Appendix Table F.4, we display estimates for finer peer group size and firm size categories. The estimates are very similar across the different categories of peer group and firm sizes for both most repetitive and high skilled occupations.
} 
suggests that our baseline peer group definition at the 3-digit occupational level is the most plausible. $^{19}$

\subsection{Heterogeneous Peer Effects}

We now provide additional evidence that peer effects in the $5 \%$ most repetitive occupations - where we have found the strongest effects - are driven primarily by peer pressure, by investigating heterogeneity in peer effects in that sector.

Age and job tenure

In the low skilled, repetitive occupations we consider, we expect that almost all the on-the-job learning takes place when workers are young or have only just joined the peer group. In Panel A of Table 8 , we therefore allow the peer effect in the $5 \%$ most repetitive occupations to differ for older (age >35 years) and younger workers (age <=35 years) and for workers who have been with the peer group for more or less than two years. Although we do find that peer effects are larger for younger workers, which is in line with knowledge spillover, we also find positive peer effects for older workers. Moreover, peer effects vary little with tenure in the peer group. Both these findings are difficult to reconcile with peer effects arising from knowledge spillover alone. It should also be noted that although the smaller peer effect for older workers is consistent with knowledge spillover, it is also in line with younger workers responding more strongly to peer pressure or suffering more from the "pain" of peer pressure than older or more experienced workers.

\footnotetext{
${ }^{19}$ As a further robustness check, we have instrumented, for the 5\% most repetitive occupations, the change in peer quality by the average quality of leavers from the peer group who in $\mathrm{t}-1$ were close to retirement age; the rationale being that leaving into retirement may be more exogenous than other reasons for the turnover of peers. This gives us a strong first stage (F-value 151.1) with expected negative sign. The IV peer effect coefficient is 0.041 , not too far off our baseline estimate of 0.064 , although imprecisely estimated and not statistically significant; see Table F.5 in the Online Appendix.
} 


\section{Symmetry of Effects}

In Panel B of Table 8 we investigate whether improvements in the average peer group quality have similar effects as deteriorations. To this end, using the peer group stayers, we regress the change in log wages on the change in peer group quality (using the pre-estimated worker fixed effects from our baseline specification) and allow this effect to vary according to whether peer group quality improves or deteriorates (see Mas and Moretti, 2009, for a similar specification). Our results show relatively symmetric effects for both improvements and deteriorations. This once again points against knowledge spillover as they primary driver behind peer effects in the repetitive sector, as it is unlikely that workers immediately "unlearn" skills when peers get worse.

\section{Low versus High Ability Workers}

In Panel $\mathrm{C}$ of Table 8, we explore whether the peer effects in wages differ for low versus high ability workers in the peer group (i.e., workers with a worker fixed effect, pre-estimated from our baseline specification, below and above the median in the firm-occupation). Like Mas and Moretti (2009), we find that peer effects are almost twice as large for low as for high ability workers. One possible explanation is that low ability workers increase their effort more than high ability workers in response to an increase in peer quality (i.e., the peer effect in productivity is higher for low than for high ability workers). If this latter does indeed explain peer effect differences between low and high ability workers, then, as Mas and Moretti (2009) emphasize, firms may want to increase peer group diversity — and maximize productivity—by grouping low ability with high ability workers.

Our model, however, also suggests an alternative interpretation; namely, that low ability workers suffer more from the pain of peer pressure than high ability workers, leading to higher peer effects in wages for low than high ability workers, even when peer effects in productivity 
are the same. ${ }^{20}$ If such "pain" is the reason for the larger peer effects among the low ability workers, then firms may prefer homogenous peer groups over diverse peer groups because they will save wage costs without lowering productivity.

\section{Bottom versus Top Peers}

Whereas all our previous specifications estimate the effect of average peer quality on wages, in Panel D of Table 8, we estimate the effect of the quality of the top and bottom workers in the peer group on wages. To do so, we split the peer group into three groups: the top $10 \%$, the middle $80 \%$, and the bottom $10 \%$ of peers based on the estimated worker fixed effects from our baseline regression. ${ }^{21}$ We then regress individual wages on the average worker fixed effect for the three groups, controlling for the same covariates and fixed effects as in our baseline specification and restricting the sample to workers in the middle group. We find that the effect of the average peer quality in the middle group on wages is similar to our baseline effect, while the average productivities of peers in the bottom or top groups have no significant effect on wages. Hence, our baseline peer effects are neither driven entirely by very bad workers nor driven entirely by very good workers. This observation rules out a simple chain production model in which team productivity is determined by the productivity of the "weakest link in the chain"; that is, the least productive worker. It also suggests that the peer effects in the $5 \%$ most repetitive occupations are not driven solely by the most productive workers in the peer group, even though

${ }^{20}$ In our model, low and high ability workers increase their effort by the same amount in response to an increase in peer ability (see equation (A.2)), meaning that the peer effect in productivity is the same for both groups. Note, however, that the rate at which higher peer ability translates into "pain" from peer pressure, $\frac{\partial P\left(e_{i}, \bar{y}_{\sim i}\right)}{\partial \bar{y}_{\sim i}}=$ $\lambda^{P}\left(m-e_{i}^{*}\right)$ varies inversely with a worker's own optimal effort $e_{i}^{*}$, which in turn varies positively with individual ability (see equation (A.4)), implying that the pain from peer pressure for a given increase in peer ability is higher for low ability than for high ability workers.

${ }^{21}$ Although these shares are quite exact in large peer groups, in small peer groups, the top and bottom do not exactly equal $10 \%$. For example, in a peer group with four workers, one worker falls at the top, one at the bottom, and two in the middle. 
these latter may increase overall peer group productivity by motivating and guiding their coworkers. $^{22}$

\section{Conclusions}

Although peer effects in the classroom have been extensively studied in the literature (see Sacerdote, 2011, for an overview), empirical evidence on peer effects in coworker productivity is as yet restricted to a handful of studies based on either laboratory experiments or real-world data from a single firm or occupation. Our study sheds light on the external validity of these studies by carrying out the first investigation to date into peer effects in a general workplace setting. Unlike the previous research, our study focuses on peer effects in wages rather than in productivity.

On average, we find only small, albeit precisely estimated, peer effects in wages, suggesting that the larger peer effects found in existing studies may not carry over to the labor market in general. Yet our results also reveal larger peer effects in low skilled occupations where coworkers can easily observe each other's output, which are exactly the occupations most often analyzed in the previous studies on peer pressure. In these types of occupations, therefore, the findings of previous studies extend beyond the specific firms or tasks which they explore. Our results also indicate that in this segment of the labor market, productivity spillovers translate into wage spillovers - a dynamic as yet unexplored in the literature — and suggest that indeed peer pressure, and not knowledge spillover, is the main source of the peer effect.

\footnotetext{
${ }^{22}$ In an interesting study in a technology-based services company, Lazear et al. (2015) find that the quality of bosses has significant effects on the productivity of their subordinates. While it might be tempting to interpret the quality of the top $10 \%$ of peers in our study as a proxy for boss quality, we prefer not to interpret our findings as informative on boss effects: first, we cannot ascertain whether more able peers are indeed more likely to become team leaders or supervisors, and second, bosses need not necessarily belong to the same occupation as their subordinates and thus need not be in the same peer group as defined by our data.
} 
Overall, we conclude that peer effects in the workplace, despite being important in some specific settings, do not importantly affect the wage setting of firms, nor do they contribute significantly to overall inequality in the labor market.

\section{References}

Abowd, John M., Francis Kramarz, and David N. Margolis. "High wage workers and high wage firms." Econometrica 67, no. 2 (1999): 251-333.

Ammermueller, Andreas, and Jörn-Steffen Pischke. "Peer effects in European primary schools: Evidence from the progress in international reading literacy study." Journal of Labor Economics 27, no. 3 (2009): 315-348.

Arcidiacono, Peter, Gigi Foster, Natalie Goodpaster, and Josh Kinsler. "Estimating spillovers using panel data, with an application to the classroom." Quantitative Economics 3, no. 3 (2012): 421-470.

Azoulay, Pierre, Joshua Graff Zivin, and Jialan Wang. "Superstar extinction." Quarterly Journal of Economics 25 (2010): 549-589.

Babcock, Philip, Kelly Bedard, Gary Charness, John Hartman, Heather Royer. "Letting down the team? Evidence of [the] social effects of team incentives. NBER Working Paper No. 16687, 2011.

Bandiera, Oriana, Iwan Barankay, and Imran Rasul. "Social incentives in the workplace." Review of Economic Studies 77, no. 2 (2010): 417-458.

Barron, John M., and Kathy Paulson Gjerde. "Peer pressure in an agency relationship." Journal of Labor Economics (1997): 234-254.

Battisti, Michele. "High wage workers and high wage peers." Ifo Working Paper No. 168, 2013.

Betts, Julian R., and Andrew Zau. "Peer groups and academic achievement: Panel evidence from administrative data." Working Paper, University of California, San Diego and Public Policy Institute of California, 2004.

Bloom, Nicholas, James Liang, John Roberts, and Zhichun Jenny Ying. "Does working from home work? Evidence from a Chinese experiment. NBER Working Paper No. 18871, 2013.

Card, David, Ana Rute Cardoso, and Patrick Kline. "Bargaining, Sorting, and the Gender Wage Gap: Quantifying the Impact of Firms on the Relative Pay of Women." Unpublished Manuscript, University of California, Berkeley, 2014.

Card, David, Jörg Heining, and Patrick Kline. "Workplace heterogeneity and the rise of West German wage inequality." Quarterly Journal of Economics 128, no. 3 (2013): 967-1015. 
Chan, Tat Y., Jia Li, and Lamar Pierce. "Compensation and Peer Effects in Competing Sales Teams.” Management Science, 60, no. 8 (2014):1965-1984.

Cornelissen, T. "Peer effects in coworker productivity." IZA World of Labor: 2016, forthcoming.

De Grip, Andries, and Jan Sauermann. "The effects of training on own and co-worker productivity: Evidence from a field experiment.” Economic Journal 122 (2012): 376-399.

Dustmann, Christian, Johannes Ludsteck, and Uta Schönberg. "Revisiting the German Wage Structure.” Quarterly Journal of Economics 124, no. 2 (2009): 843-881.

Falk, Armin, and Andrea Ichino. "Clean evidence on peer effects." Journal of Labor Economics, 24, no. 1 (2006): 39-57.

Gathmann, Christina, and Uta Schönberg. "How general is human capital? A task-based approach.” Journal of Labor Economics, 28, no.1 (2010): 1-49.

Gould, Eric D., and Eyal Winter. "Interactions between workers and the technology of production: Evidence from professional baseball." Review of Economics and Statistics 91, no. 1 (2009): 188-200.

Gould, Eric D., Victor Lavy, and M. Daniele Paserman. "Does immigration affect the long-term educational outcomes of natives? Quasi-experimental evidence." Economic Journal 119, no. 540 (2009): 1243-1269.

Guryan, Jonathan, Kory Kroft, and Matthew J. Notowidigdo. "Peer effects in the workplace: Evidence from random groupings in professional golf tournaments." American Economic Journal: Applied Economics 1, no. 4 (2009): 34-68.

Hanushek, Eric A., John F. Kain, Jacob M. Markman, and Steven G. Rivkin. "Does peer ability affect student achievement?" Journal of Applied Econometrics 18, no. 5 (2003): 527-544.

Herbst, Daniel, and Alexandre Mas. "Peer effects on worker output in the laboratory generalize to the field." Science 350 no. 6260 (2015): 545-549.

Hoxby, Caroline. "Peer effects in the classroom: Learning from gender and race variation." NBER Working Paper No. 7867, 2000.

Ichino, Andrea, and Giovanni Maggi. "Work environment and individual background: Explaining regional shirking differentials in a large Italian firm." Quarterly Journal of Economics 115, no. 3 (2000): 1057-1090.

Jackson, Clement Kirabo, and Elias Bruegmann. "Teaching students and teaching each other: The importance of peer learning for teachers." American Economic Journal: Applied Economics 1, no. 4 (2009): 85-108.

Kandel, Eugene, and Edward P. Lazear. "Peer pressure and partnerships." Journal of Political Economy (1992): 801-817.

Kaur, Supreet, Michael Kremer, and Sendhil Mullainathan. "Self-control and the development of work arrangements." American Economic Review, Papers and Proceedings 100, no. 2 (2010): 624-628. 
Lavy, Victor, and Analia Schlosser. "Mechanisms and impacts of gender peer effects at school." American Economic Journal: Applied Economics 3, no. 2 (2011): 1-33.

Lavy, Victor, M. Daniele Paserman, and Analia Schlosser. "Inside the black box of ability peer effects: Evidence from variation in the proportion of low achievers in the classroom." Economic Journal 122, no. 559 (2012): 208-237.

Lazear, Edward P., Kathryn L. Shaw, and Christopher T. Stanton. "The value of bosses.” Journal of Labor Economics, 33, no. 4 (2015), pp. 823-861.

Lengermann, Paul. "Is it who you are, where you work, or with whom you work? Reassessing the relationship between skill segregation and wage inequality." LEHD Technical Paper No. 10, U.S. Census Bureau, Center for Economic Studies, 2002.

Lindquist, Matthew, Jan Sauermann, and Yves Zenou. "Network effects on worker productivity." CEPR Discussion Paper No. 10928, 2015.

Lucas, Robert E., Jr. "On the mechanics of economic development." Journal of Monetary Economics 22, no. 1 (1988): 3-42.

Manski, Charles F. "Identification of endogenous social effects: The reflection problem." Review of Economic Studies 60, no. 3 (1993): 531-542.

Marshall, Alfred. Principles of economics. New York: Macmillan, 1890.

Mas, Alexandre, and Enrico Moretti. "Peers at work." American Economic Review 99, no. 1 (2009): 112-145.

McEwan, Patrick J. "Peer effects on student achievement: Evidence from Chile." Economics of Education Review 22, no. 2 (2003): 131-141.

Moretti, Enrico. "Workers' Education, Spillovers, and Productivity: Evidence from Plant-level Production Functions.” The American Economic Review 94 no.3 (2004): 656-690.

Sacerdote, Bruce. "Peer effects in education: How might they work, how big are they, and how much do we know thus far?" Handbook of the Economics of Education 3 (2011): 249-277.

Serafinelli, Michel. "Good firms, worker flows, and productivity." Unpublished Manuscript, University of California, Berkeley, 2013.

Vigdor, Jacob, and Thomas Nechyba. "Peer effects in North Carolina public schools." In: Woessmann, L., Peterson, P.E. (Eds.), Schools and the equal opportunity problem (pp. 73-101). Cambridge, MA: MIT Press, 2007.

Waldinger, Fabian. Quality matters: The expulsion of professors and the consequences for PhD student outcomes in Nazi Germany]“ Journal of Political Economy, 118, no. 4 (2010): 787-831, 2010.

Waldinger, Fabian. "Peer effects in science: Evidence from the dismissal of scientists in Nazi Germany.“ Review of Economic Studies 79, no. 2 (2012): 838-861. 


\begin{tabular}{|c|c|c|c|}
\hline & $\begin{array}{c}\text { all } \\
\text { occupations }\end{array}$ & $\begin{array}{c}5 \% \text { most } \\
\text { repetitive } \\
\text { occupations }\end{array}$ & $\begin{array}{c}10 \% \text { most } \\
\text { skilled } \\
\text { occupations }\end{array}$ \\
\hline \multicolumn{4}{|l|}{ Skill Content } \\
\hline Share without postsecondary education & 0.17 & 0.47 & 0.04 \\
\hline Share with university degree & 0.18 & 0.01 & 0.80 \\
\hline \multicolumn{4}{|c|}{ To what extent does the following occur in your daily work? $(0=$ never, $\ldots, 4=$ all the time) } \\
\hline need to learn new tasks and think anew & 2.25 & 1.36 & 2.98 \\
\hline need to experiment and try out new ideas & 1.80 & 0.96 & 2.56 \\
\hline \multicolumn{4}{|l|}{ Peer Group Size } \\
\hline median & 3 & 4 & 3 \\
\hline mean & 9.3 & 12.3 & 13.1 \\
\hline \multicolumn{4}{|l|}{ Wage Flexibility } \\
\hline St. dev. of log real wage (imputed) & 0.472 & 0.326 & 0.371 \\
\hline St. dev. of log real wage residual ${ }^{\text {a) }}$ & 0.377 & 0.308 & 0.365 \\
\hline Within-peer group st. dev. of log real wage residual ${ }^{\text {a) }}$ & 0.243 & 0.200 & 0.269 \\
\hline Probability of $>5 \%$ real wage cut (peer group stayers) & 0.088 & 0.130 & 0.034 \\
\hline Average wage growth & 0.022 & 0.016 & 0.023 \\
\hline
\end{tabular}

Note: The table compares all occupations ( $\mathrm{N}=12,832,842$ worker-year observations) with the $5 \%$ most repetitive occupations ( $N=681,391)$ and the $10 \%$ most skilled occupations $(N=1,309,070)$. See Appendix Table F.3 for a full list of occupations, and Section 3.3 of the text for the definition of "repetitive" and "skilled" occupations.

a) Residual from a log-wage regression, after controlling for aggregate time effects, education, and quadratics in firm tenure and age.

Data Source: Social Security Data, One Large Local Labor Market, 1989-2005, combined with information from Qualification and Career Survey 1991/1992. 


\section{Panel structure}

(i)
No. of workers

No. of firms

Number of peer groups (occupations within firm-years) Average number of time periods per worker

Number of peer groups per firm-year Average number of employers per worker Average number of occupations per worker

Share of mobility group with identified firm fixed effects

Share of mobility group with identified firm-time fixed effects

Share of mobility group with identified firm-occupation fixed effects
$2,115,544$

89,581

$1,387,216$

6.07

2.30

1.60

1.40

0.995

0.994

0.983

\section{Variation in wages, peer quality and worker turnover}

\begin{tabular}{rrr} 
(xi) & St. dev. worker fixed effect & 0.32 \\
(xii) & St. dev. average peer fixed effect & 0.24 \\
(xii) & St. dev. change of average peer fixed effect from t-1 to t & 0.09 \\
(xiv) & St. dev. change of average peer fixed effect from t-1 to t - Movers & 0.20 \\
(xv) & St. dev. change of average peer fixed effect from t-1 to t - Stayers & 0.06 \\
(xvi) & Share of worker-year observations in peer groups with turnover & 0.90 \\
(xvii) & Average share of workers replaced by turnover & 0.20 \\
(xviii) & Correlation worker fixed effect / average peer fixed effect & 0.64 \\
(ixx) & Correlation worker fixed effect / firm-time effect & 0.14 \\
(xx) & Correlation worker fixed effect / firm-occupation effect & 0.16 \\
\hline
\end{tabular}

Note: The table shows descriptive statistics describing the panel structure of the data set, as well as the variation in wages, peer quality and worker turnover which we exploit in subsequent estimations. $\mathrm{N}=12,832,842$.

Data Source: Social Security Data, One Large Local Labor Market, 1989-2005. 
Table 3: Peer Effects in the Full Sample

\begin{tabular}{lccc}
\hline & $\begin{array}{c}(1) \\
\text { observables, occupation- } \\
\text { year and firm fixed } \\
\text { effects }\end{array}$ & $\begin{array}{c}\text { plus firm-occupation } \\
\text { fixed effects }\end{array}$ & $\begin{array}{c}\text { (3) } \\
\text { plus firm-occupation } \\
\text { and firm-year fixed } \\
\text { effects }\end{array}$ \\
\hline Average peer fixed effect & 0.148 & 0.066 & 0.011 \\
Worker Fixed Effects & $(0.002)$ & $(0.002)$ & $(0.001)$ \\
Occupation X Year Effects & Yes & Yes & Yes \\
Firm Effects & Yes & Yes & Yes \\
Occupation X Firm Effects & Yes & - & - \\
Firm X Year Effects & - & Yes & Yes \\
\hline
\end{tabular}

Note: The table shows the effect of average peer quality on the individual log wage in the overall sample. Peer quality is measured as the average fixed worker effect of the coworkers in the same 3digit occupation at the same firm in the same point of time. In column (1), we only control for worker fixed effects, firm fixed effects, occupation-by-year fixed effects, and quadratics in age and firm tenure. We then successively add firm-occupation fixed effects (column (2)), and firm-by-year fixed effects (column (3)). Specification (3) corresponds to the baseline specification described in equation (4) in the text. Coefficients can approximately be interpreted as elasticities, and the coefficient of 0.011 in the baseline specification in column (3) implies that a $10 \%$ increase in average peer quality increases wages by $0.1 \%$. Bootstrapped standard errors with clustering at firm level in parentheses. $N=12,832,842$.

Data Source: Social Security Data, One Large Local Labor Market, 1989-2005. 
Table 4: Peer Effects in Sub-Samples of Occupations

(1) (2) (3)

(4)

Panel A: Peer Effects for Sub-Samples of Low Skilled Occupations

\begin{tabular}{|c|c|c|c|c|}
\hline & \multicolumn{3}{|c|}{ Baseline specification of eq. (4) } & $\begin{array}{l}\text { Within-Peer Group } \\
\text { Estimator of eq. (6) }\end{array}$ \\
\hline & $\begin{array}{c}5 \% \text { most repetitive } \\
\text { occupations }\end{array}$ & As in case studies & Low learning content & $\begin{array}{c}5 \% \text { most repetitive } \\
\text { occupations }\end{array}$ \\
\hline Average peer fixed effect & $\begin{array}{c}0.064 \\
(0.0070)\end{array}$ & $\begin{array}{c}0.067 \\
(0.0116)\end{array}$ & $\begin{array}{c}0.052 \\
(0.0031)\end{array}$ & $\begin{array}{c}0.061 \\
(0.006)\end{array}$ \\
\hline \multicolumn{5}{|c|}{ Panel B: Peer Effects for Sub-Samples of High Skilled Occupations } \\
\hline & \multicolumn{3}{|c|}{ Baseline specification of eq. (4) } & $\begin{array}{l}\text { Within-Peer Group } \\
\text { Estimator of eq. (6) }\end{array}$ \\
\hline & $\begin{array}{l}10 \% \text { most skilled } \\
\text { occupations }\end{array}$ & $\begin{array}{l}10 \% \text { most innovative } \\
\text { occupations }\end{array}$ & High learning content & $\begin{array}{c}10 \% \text { most skilled } \\
\text { occupations }\end{array}$ \\
\hline Average peer fixed effect & $\begin{array}{c}0.013 \\
(0.0039)\end{array}$ & $\begin{array}{c}0.007 \\
(0.0044)\end{array}$ & $\begin{array}{c}0.017 \\
(0.0028)\end{array}$ & $\begin{array}{c}0.016 \\
(0.004)\end{array}$ \\
\hline
\end{tabular}

Note: The first three columns of the table replicate the baseline peer effects estimates of column (3) in Table 3 for different occupational groups-see Appendix Table F.3 for a full list of occupations in each of the sub-samples used in this table, and section 3.3 in the text for a description of the way in which the different sub-samples were constructed. In panel A, column (1), we show the effect for the $5 \%$ most repetitive occupations. In panel A, column (2), we show the effect for agricultural helpers, cashiers and data entry workers, which have been used in related case-studies on peer effects in the workplace. In panel A, column (3), we report the effect for occupations characterized by standardized tasks (as the $5 \%$ most repetitive occupations) and limited learning content (i.e., cashiers, warehouse workers, drivers, removal workers, cleaners, agricultural helpers, and waiters). In panel $B$, column (1) we present results for the $10 \%$ most skilled occupations, as measured by the share of workers with a college degree in that occupation. In panel B, column (2) we present results for the $10 \%$ most innovative occupations, defined by occupation averages of workers' responses to an index of how frequently they need to experiment with new ideas. In panel B, column (3) we present results for occupations with complex tasks and a high learning content (such as doctors, lawyers, scientists, teachers, and academics). In column (4), we present the within peer group estimate for, as in column (1), the 5\% most repetitive and $10 \%$ most skilled occupations, see equation (6) in the text. The within-estimator is based on pre-estimated worker fixed effects from the baseline model in equation (4) in the text. Bootstrapped standard errors with clustering at firm level in parentheses. $\mathrm{N}=12,832,842$.

Data Source: Social Security Data, One Large Local Labor Market, 1989-2005. 
(1)

\section{Panel A: 5\% Most Repetitive Occupations}

Average peer fixed effect

Average peer fixed effect, $t+1$

Average peer fixed effect, $t+2$

Average peer fixed effect, $t-1$

Average peer fixed effect, $t-2$

Observations:

\section{Panel B: $10 \%$ Most Skilled Occupations}

Average peer fixed effect

Average peer fixed effect, $t+1$

Average peer fixed effect, $t+2$

Average peer fixed effect, $t-1$

Average peer fixed effect, $t-2$

Observations:
0.066
(0.005)
0.006
(0.005)
0.001
(0.005)

0.046

(0.005)

0.036

(0.007)

0.003

(0.006)

0.004

(0.006)

$$
\begin{gathered}
0.0006 \\
(0.004) \\
-0.007 \\
(0.004)
\end{gathered}
$$

0.008

(0.005)

$-0.001$

(0.005)

392,937

392,937

250,911

$\begin{array}{ccc}0.017 & 0.020 & 0.016 \\ (0.003) & (0.004) & (0.005)\end{array}$

$-0.002$

0.007

(0.004)

(0.006)

$-0.006$

$-0.017$

(0.003)

$(0.007)$

-0.002
$0.004)$

0.008

(0.005)

(0.005)

0.012

(0.006)

815,052

Note: The table investigates the dynamic effects of average peer quality on log wages, based on preestimated fixed effects from the baseline specification. Panel A shows results for the group of the $5 \%$ most repetitive occupations, as in column (1), Panel A of Table 4. Panel B reports results for the group of the $10 \%$ most skilled occupations, as in column (1), Panel B, of Table 4. In column (1) we add the peer quality of the focal worker's future peers from the periods $t+1$ and $t+2$ to our baseline specification as a placebo test. In column (2) we add the average fixed effects of the lagged peer group to equation (4). In column (3) we present a more complete specification including both leads and lags. Bootstrapped standard errors with clustering at firm level in parentheses.

Data Source: Social Security Data, One Large Local Labor Market, 1989-2005. 




Note: The table reports effects on log wages of the peer quality in peer groups that are economically or geographically close (or far) to the focal worker's own peer group. Column (1) shows the results for the group of the $5 \%$ most repetitive occupations, as in column (1), Panel A of Table 4. Column (2) reports results for the group of the $10 \%$ most skilled occupations, as in column (1), Panel B, of Table 4. In rows (i) and (ii) of Panel A, we report results when the peer group consists of workers from a randomly chosen 3-digit occupation (other than the worker's own occupation) in the same firm; distinguishing whether the randomly assigned peer group is from an economically "close" or an economically "far" occupation, where economic closeness is measured by worker flows between occupations in the overall sample. A pair of occupations is defined as "close" if the proportion of workers switching between these occupations is above median, and "far" if it is below median. This specification drops firm-year observations with only one occupation. In rows (iii) and (iv) of Panel A, we show the effect of peer quality in the economically closest and farthest 3-digit occupation (other than the worker's own occupation) in the same firm, where closeness is again measured by worker flows between occupations in the overall sample. This specification is based on firm-year observations with at least three occupations per firm. In Panel $B$, we report results when adding peer quality of workers in peer groups in other firms that are economically close to the focal worker's peer group to our baseline specification, where we again measure economic closeness by worker flows in the overall sample. In row (ii), we report the coefficient on the average worker fixed effect of workers who in year $t$ are in peer groups (firm-occupation combinations) in other firms that at any point during the observation period have exchanged workers with the focal worker's peer group. In row (iii), we report the coefficient on the peer quality of the past peers of recent joiners to the focal worker's peer group. For this we first identify the peer groups from which new joiners to the focal peer group came from (i.e., the peer groups in which the joiners were in $t-1$ ) and compute the average worker fixed effect of the workers who were in these peer groups in t-1 but who did not join the focal peer group t. In Panel C, we augment the baseline model by adding the average peer quality of workers living in the same municipality who are employed in the same occupation (but not necessarily in the same firm) as the focal worker. This equation is run on a sample for the period 1999-2010 because the indicator of the municipality of residence is only available from 1999. Bootstrapped standard errors with clustering at firm level in parentheses.

Data Source: Social Security Data, One Large Local Labor Market, 1989-2005. 


\begin{tabular}{|c|c|c|c|}
\hline & & $(1)$ & $(2)$ \\
\hline & & $\begin{array}{c}5 \% \text { Most Repetitive } \\
\text { Occupations }\end{array}$ & $\begin{array}{l}\text { 10\% Most Skilled } \\
\text { Occupations }\end{array}$ \\
\hline (i) & Baseline & 0.064 & 0.013 \\
\hline & & $(0.0070)$ & (0.0039) \\
\hline (ii) & Separate effect for stayers & 0.061 & 0.014 \\
\hline & & $(0.006)$ & $(0.003)$ \\
\hline (iii) & Separate effect for movers & 0.073 & 0.006 \\
\hline & & $(0.006)$ & $(0.004)$ \\
\hline (iv) & Wage not imputed & 0.086 & 0.017 \\
\hline & & $(0.007)$ & $(0.007)$ \\
\hline (v) & Varying coefficients on observables & 0.082 & 0.007 \\
\hline & & $(0.008)$ & $(0.004)$ \\
\hline (vi) & Expansion of sample to larger region with & 0.082 & 0.014 \\
\hline & additional rural areas & $(0.008)$ & $(0.002)$ \\
\hline (vii) & Include peer observables & 0.071 & 0.010 \\
\hline & & $(0.006)$ & $(0.005)$ \\
\hline Bype & & & \\
\hline (viii) & Peer groups size $<=10$ & 0.068 & 0.014 \\
\hline & & $(0.002)$ & $(0.001)$ \\
\hline (ix) & Peer groups size $>100$ & 0.081 & 0.014 \\
\hline & & $(0.004)$ & $(0.003)$ \\
\hline Altern & definitions & & \\
\hline$(\mathrm{x})$ & 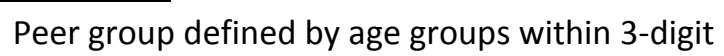 & 0.032 & 0.006 \\
\hline & occupations & $(0.007)$ & $(0.004)$ \\
\hline
\end{tabular}

Note: The table reports a number of robustness checks for the effect of average peer quality on log wages. The first column refers to the group of the $5 \%$ most repetitive occupations and the second column refers to the group of the $10 \%$ most skilled occupations. For comparison, we replicate the results from the respective baseline specifications of column (1), Table 4 in row (i). In rows (ii) and (iii), we show separate peer effects for stayers and movers. Workers are defined as stayers in periods when they are in the same firm and occupation in period $t$ as in period $t-1$, and as movers when they switch the firm or occupation between periods t-1 and t. In row (iv), we do not impute censored wage observations. In row (v), we allow the coefficients on the observable characteristics (quadratics in age and firm tenure) to vary between the $5 \%$ most repetitive (or $10 \%$ most skilled) occupations and the remaining occupations. In row (vi) we extend our estimation sample to include not only the metropolitan area of Munich, but also additional surrounding rural areas. In row (vii), we augment the baseline model by adding peer averages of observed characteristics (firm tenure, age, and schooling). In rows (viii) and (ix), we report the peer effect coefficient for small and large peer groups respectively. In row $(x)$, we report results for an alternative narrower peer group definition at the 3-digit-occupation-age-firm level. Bootstrapped standard errors with clustering at firm level in parentheses. $\mathrm{N}=12,832,842$.

Data Source: Social Security Data, One Large Local Labor Market, 1989-2005. 
Table 8: Heterogeneous Peer Effects (5\% Most Repetitive Occupations)

Panel A: Heterogenous Effects by age and peer group tenure

\begin{tabular}{lcc} 
& age $<=35$ years & age $>35$ years \\
\cline { 2 - 3 } Average peer fixed effect & 0.081 & 0.053 \\
& $(0.005)$ & $(0.005)$ \\
& & \\
\cline { 2 - 3 } Average peer fixed effect & 0.058 & 0.066 \\
& $(0.007)$ & $(0.006)$
\end{tabular}

Panel B: Symmetry of Peer Effects (First Differences, Peer Group Stayers, Pre-Estimated Effects)

Negative Change Positive Change

\begin{tabular}{ccc}
\cline { 2 - 3 } Change in average peer fixed effect & 0.055 & 0.048 \\
& $(0.010)$ & $(0.008)$
\end{tabular}

Panel C: Heterogeous Effects by Relative Position within the Peer Group

\begin{tabular}{ccc} 
& focal worker below & focal worker above \\
& median & median \\
\cline { 2 - 3 } Average peer fixed effect & 0.066 & 0.032 \\
& $(0.006)$ & $(0.006)$
\end{tabular}

Panel D: Distinguishing between Top vs. Bottom Peers (pre-estimated)

\begin{tabular}{lc} 
& top vs. bottom peers \\
\cline { 2 - 2 } Average fixed effect of middle $80 \%$ peers & 0.072 \\
& $(0.0045)$ \\
Average fixed effect of top $10 \%$ of peers & 0.004 \\
& $(0.0018)$
\end{tabular}

Average fixed effect of bottom $10 \%$ of peers $\quad 0.007$

(0.0017)

Note: The table investigates possible heterogeneous effects of peer quality in the $5 \%$ most repetitive sector. In Panel A we allow the effect of average peer quality on log wages to differ between workers below and above age 35, and between workers who have been in the peer group more and less than 2 years. In Panel B we investigate whether improvements and deteriorations in average peer quality have similarly sized effects. To do this, we adopt an approach similar to Mas and Moretti (2009) and regress, for peer group stayers, the change in log wages on the change in peer group quality (using the preestimated worker fixed effects from our baseline specification), and allow this effect to vary according to whether peer group quality improved or deteriorated. In Panel $\mathrm{C}$ we let the peer effect vary by whether the focal worker is above or below the peer-group mean of ability (as measured by the pre-estimated worker fixed effects from the baseline model). In Panel $D$, we split the worker's peers up into the middle $80 \%$, top $10 \%$ and bottom $10 \%$ according to their ability ranking. This specification is again based on preestimated worker fixed effects, and is run on the sample for the middle $80 \%$ of workers only.

Data Source: German Social Security Data, One Large Local Labor Market, 1989-2005. 
Figure 1: Variablity of Wages Across and Within Peer Groups.

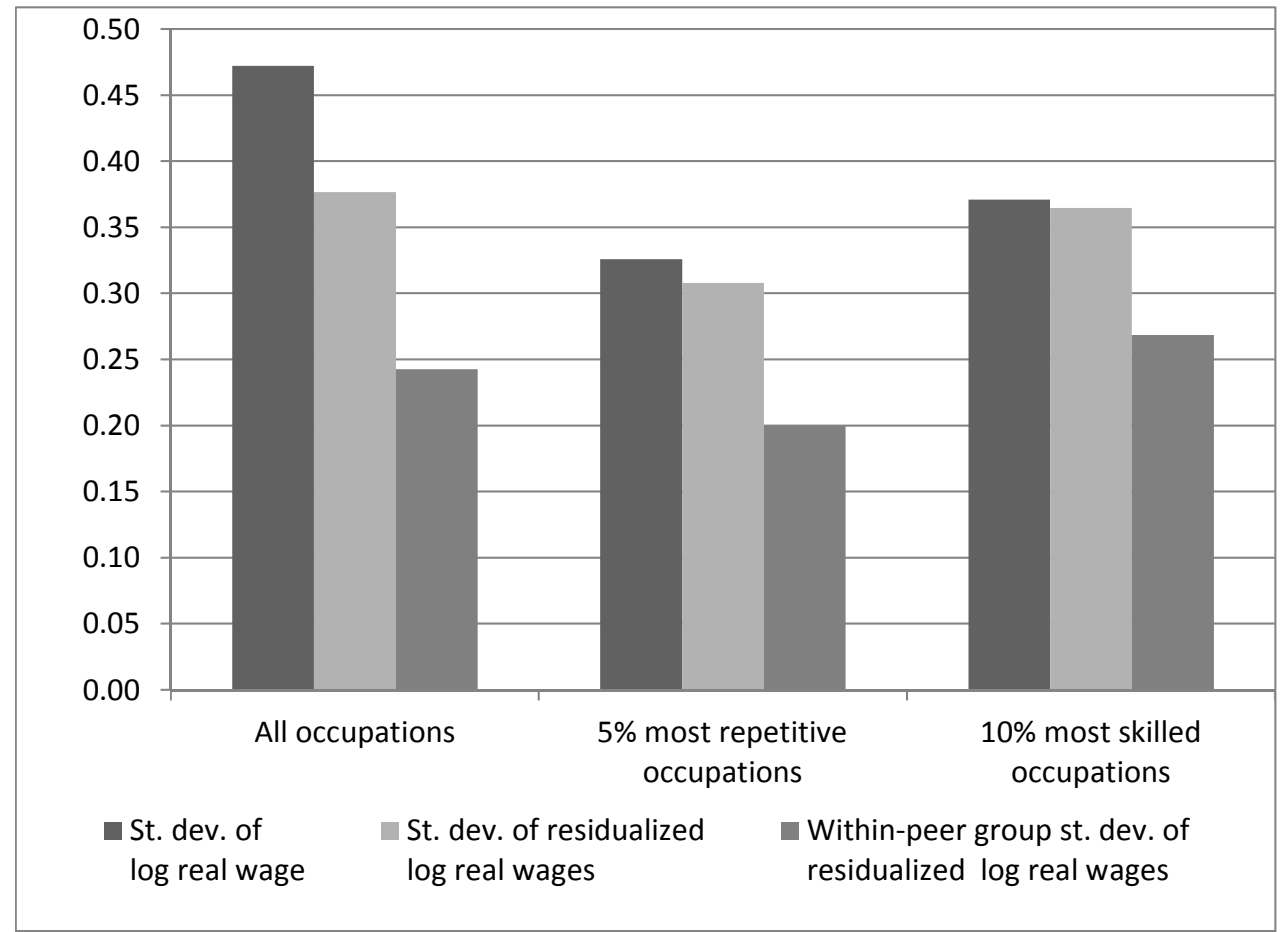

Note: The figure compares all occupations ( $\mathrm{N}=12,832,842)$, the $5 \%$ most repetitive occupations $(\mathrm{N}=681,391)$, and the $10 \%$ most skilled occupations $(\mathrm{N}=1,309,070)$ in terms of the variability of wages. Residualized wages are computed from a log-wage regression controlling for aggregate time effects, education, and quadratics in firm tenure and age.

Data Source: German Social Security Data, One Large Local Labor Market, 1989-2005.

Figure 2: Variation of the Change in Peer Quality

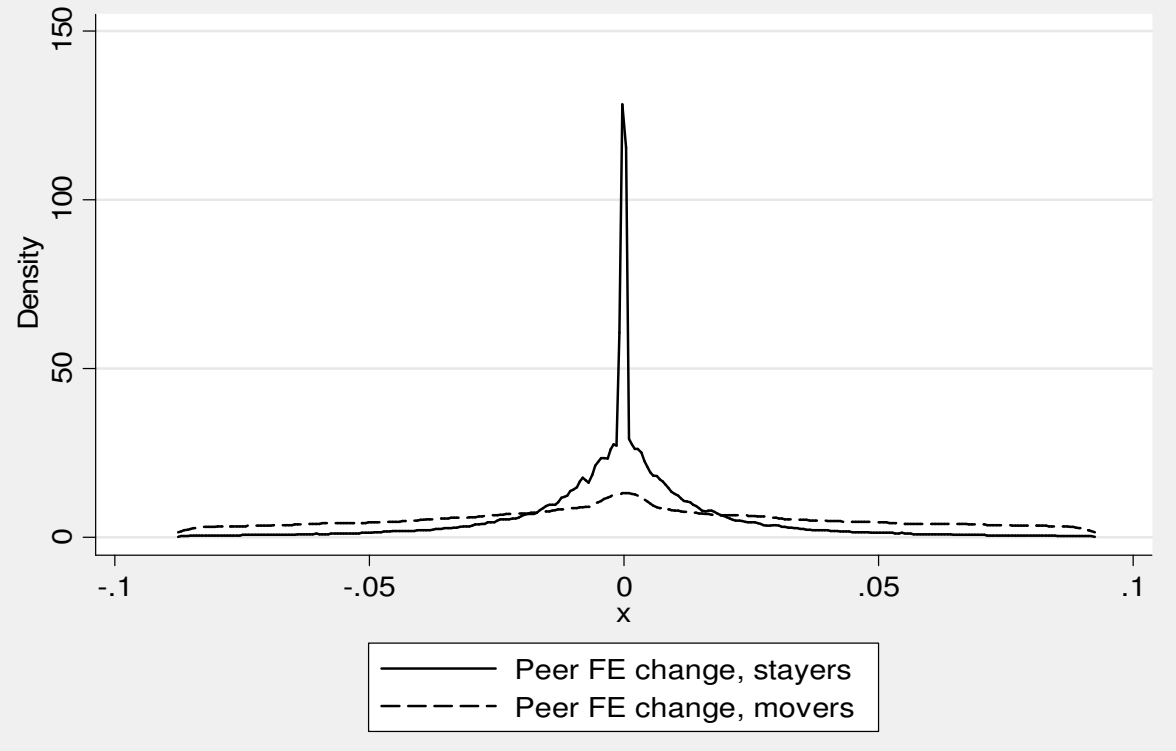

Note: The figure plots a kernel density estimate of the change in the average peer fixed effect (FE) separately for peer group stayers and peer group movers. Peer group quality varies more strongly for movers. For stayers, there is a mass point at zero, corresponding to stayers in peer groups that had no turnover. The figure is trimmed at the $5 \%$ and $95 \%$ percentile of the distribution.

Data Source: German Social Security Data, One Large Local Labor Market, 1989-2005. 
Figure 3: Additional heterogeneity of the peer efffect across bins of the repetitive and skilled index

Part A: Peer effect against repetitiveness index

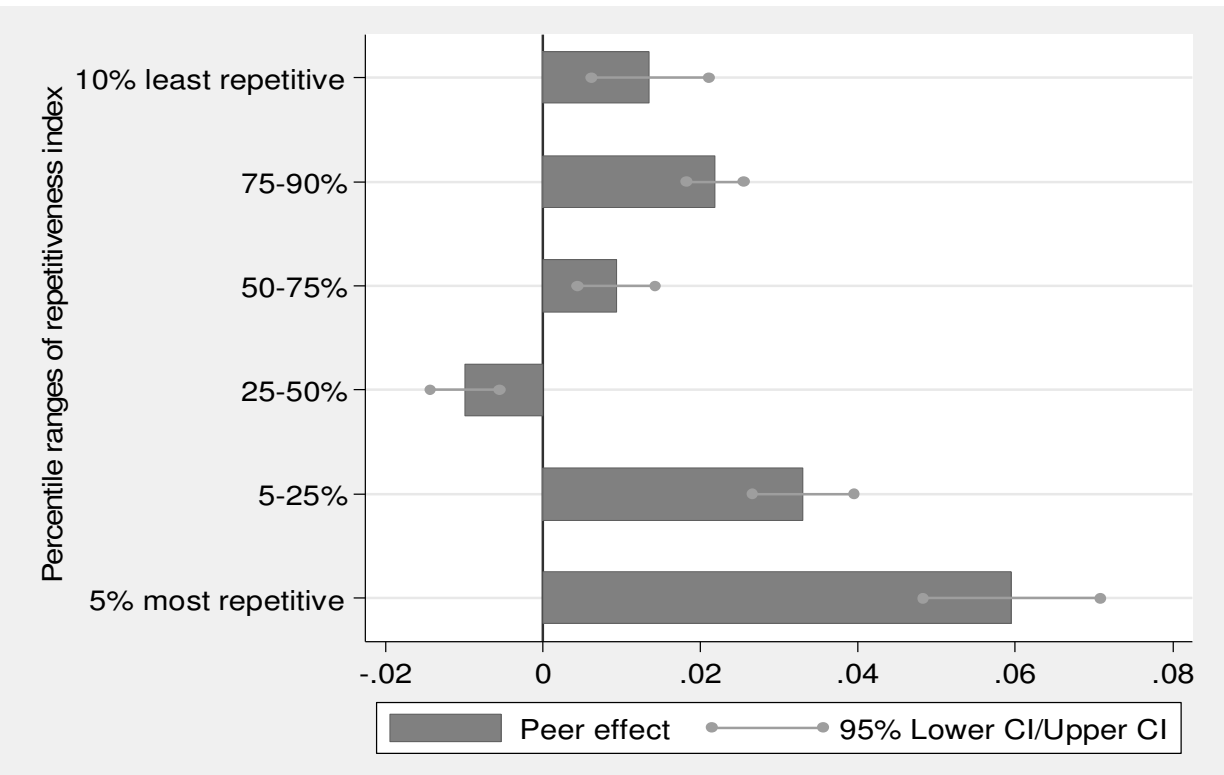

Part B: Peer effect against skill index

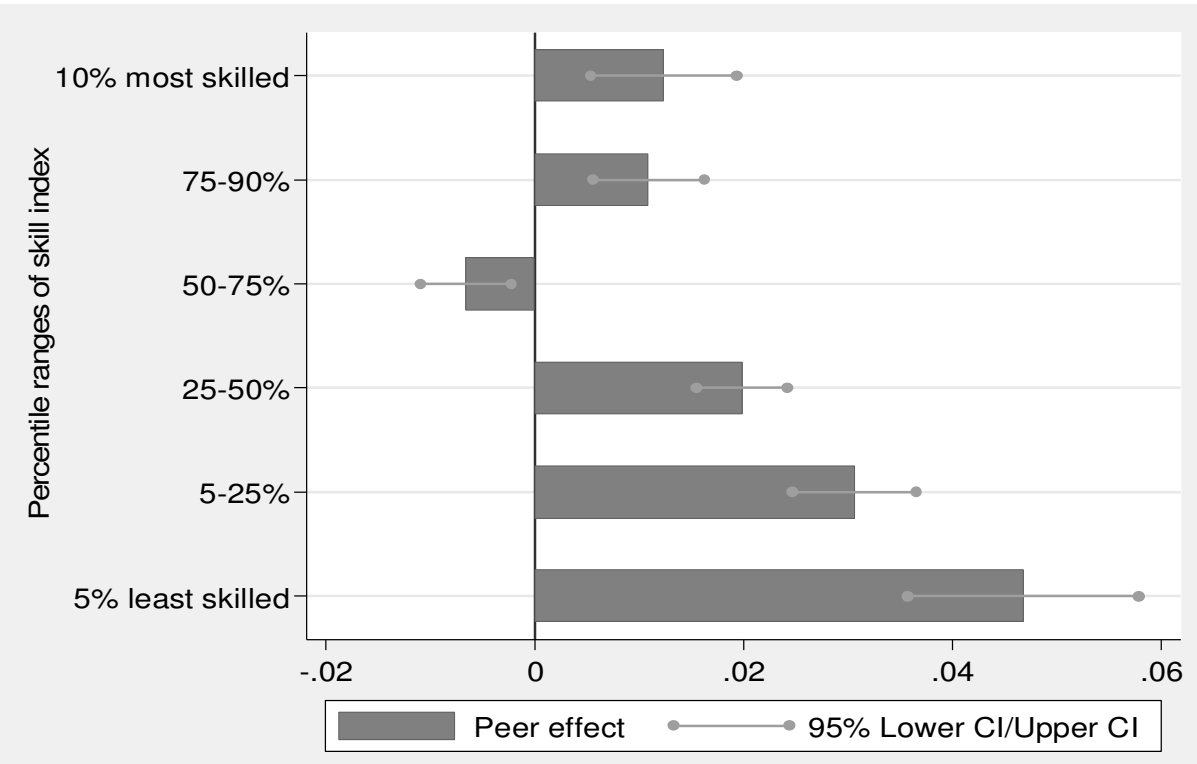

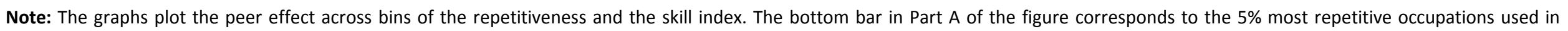


Table 4).

Data Source: German Social Security Data, One Large Local Labor Market, 1989-2005. 

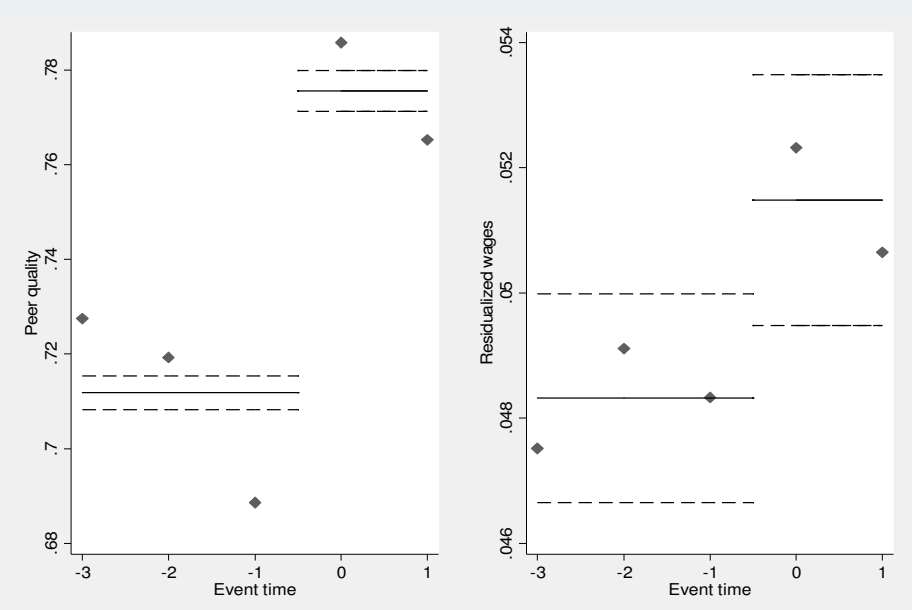

Part B: Fall in peer quality - Stayers
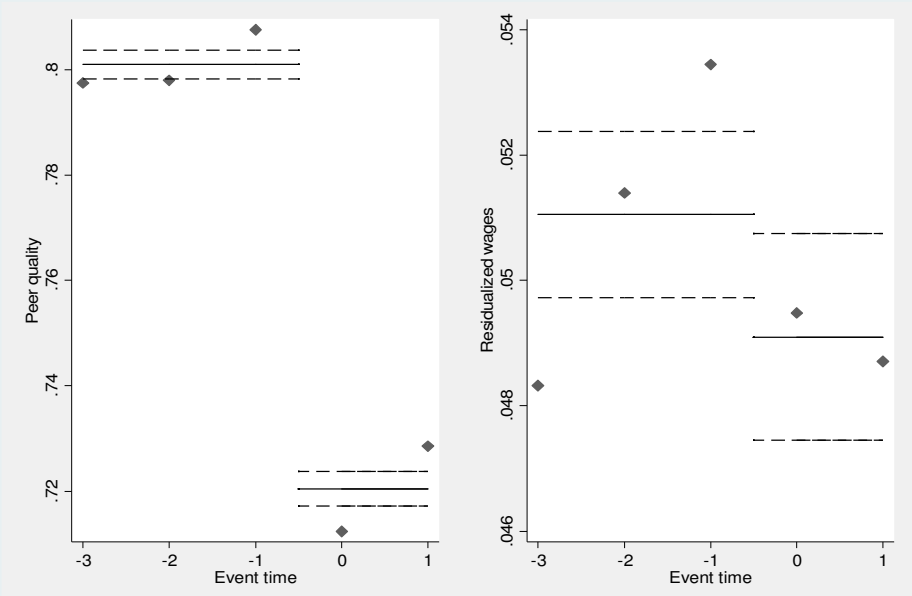

Part C: Rise in peer quality - Movers


Note: The figures show, for the $5 \%$ most repetitive occupations, the evolution of peer quality with an exceptionally large rise and fall in peer quality (greater than 0.055 from period -1 to period 0 ) on the left hand side, and the corresponding evolution of residualized wages for peer group stayers (in Parts A and B) in these peer groups on the right hand side. Average peer quality and residualized wages are shown three periods before and two periods after the large change in peer quality. Part $\mathrm{C}$ shows the evolution of peer quality and residualized wages for individuals who have moved peer group in period 0 and experienced an accompanying rise in peer quality of greater than .10, but have stayed in the same peer group in the pre and post periods. Residualised wages have been obtained by a regression of the wage level on fixed effects and observables and are purged of the observables and fixed effects included in baseline equation (4) in the text (except for peer effects, which are not netted out). Sample sizes: 3432 individuals (Part A), 326 individuals (Part B), 4989 individuals (Part C).

Data Source: German Social Security Data, One Large Local Labor Market, 5\% most repetitive occupations, 1989-2005. 